\title{
Self-Reinforced Polypropylene Composites based on Discontinuous Tapes - An Experimental and Numerical Study of the Influence of Tape Length
}

\author{
Stergios Goutianos ${ }^{1} \cdot$ Norbert O. Cabrera ${ }^{2} \cdot$ Ben Alcock $^{3} \cdot$ Neil Reynolds $^{4} \cdot$ Ton Peijs $^{4}$ (D)
}

Received: 20 September 2019 / Accepted: 21 October 2020 / Published online: 3 November 2020

(c) The Author(s) 2020

\begin{abstract}
The creation of highly oriented, coextruded polypropylene (PP) tapes allows the production of recyclable self-reinforced polypropylene (SRPP) or all-PP composites, with a large temperature processing window and high volume reinforcement content $(\sim 90 \%)$. The objective of this research is to assess the performance potential of SRPP composites based on discontinuous or short tapes. For this, the critical tape length for effective mechanical reinforcement of aligned discontinuous PP tapes was determined, while the stress transfer from PP matrix to PP tape was investigated in single tape model composites in combination with an optical strain mapping technique. Mechanical behaviour of both single tape as well as aligned tape model composites was evaluated using finite element analysis (FEA) and used to predict the properties of randomly oriented short tape composites. These discontinuous tape SRPP composites may be of interest from a manufacturing as well as recycling point of view. In terms of manufacturing, such systems are of interest as they may show improved formability during stamping or compression moulding operations while from a recycling point of view it would allow the re-use of production waste like cuttings of fabrics or tapes.
\end{abstract}

Keywords Self-reinforced polypropylene $\cdot$ Short-fibre composites $\cdot$ Stress transfer . Recycling $\cdot$ Mechanical properties $\cdot$ Finite element analysis

This paper is dedicated to the memory of Dr. Norbert Cabrera.

Ton Peijs

t.peijs@warwick.ac.uk

Stergios Goutianos

stergios.goutianos@ntnu.no

1 Department of Manufacturing and Civil Engineering, Norwegian University of Science and Technology, Teknologivegen 22, 2815 Gjøvik, Norway

2 School of engineering and Materials Science, Queen Mary University of London, Mile End Road E1 4NS London, UK

3 Materials and Nanotechnology SINTEF Industry, 0314 Oslo, Norway

4 WMG, Materials Engineering Centre, University of Warwick, CV4 7AL Coventry, UK 


\section{Introduction}

Short or discontinuous fibre reinforced thermoplastics have been developed largely to fill the property gap between continuous fibre laminates and unreinforced polymers used largely in non-load bearing applications [1, 2]. Short fibre reinforced plastics (SFRP) have a number of advantages as an engineering material. If the fibres are sufficiently long, mechanical property levels can approach those of continuous fibre systems at similar fibre loading, while similar to unreinforced polymers they have the ability to be flow moulded into more complex shapes.

In addition, short fibre reinforced plastics are easier and cheaper to produce and recycle than continuous fibre reinforced composites. The compromise between cost and performance allows short fibre reinforced thermoplastics to be used in a large number of applications. They are ideal for applications for which stiffness and toughness is important and high volume production and recycling are key. One of the greatest advantages to short fibre reinforced plastics is their ease of processing and reprocessing. Compression or injection moulding production techniques, which have low cycle times and can be fully automated together with the ability to recycle production scrap, offer significant cost benefits compared to thermoset based compounds or metals. Because of this, short fibre reinforced plastics are often the material of choice in the automotive, rail, electrical and electronic, and consumer goods industry.

In recent years, mono-material concepts such as self-reinforced polymer (SRP) composites or single-polymer composites based on oriented polymer fibres or tapes bonded together by a polymer of similar origin have emerged as promising new engineering plastics for lightweight components [3-5]. Besides competitive mechanical properties, notably toughness and impact strength, these materials have added end-of-life benefits since, upon recycling and remelting, a polymer blend is obtained which can be reused to make again SRPs, or alternatively, be used for other polymer applications. SRP concepts have been proposed for a wide range of polymer systems including polypropylene (PP) [6-8], poly(ethylene terephthalate) (PET) [9-11], polyethylene (PE) [12, 13], polylactic acid (PLA) [14, 15], liquid crystal polymer (LCP) [16], aramid [17] and cellulose $[18,19]$.

So far from a commercial point of view PP has been the most successful. One manufacturing route for self-reinforced polypropylene (SRPP) composites is based on coextruded tapes [4, 20, 21]. These coextruded tapes are 100\% PP-based and highly oriented thus providing high strength and high stiffness $(\sim 500 \mathrm{MPa}$ and $15 \mathrm{GPa})$ compared to isotropic PP ( $\sim 20 \mathrm{MPa}$ and $1.5 \mathrm{GPa})$ and are coated by coextrusion with a thin layer of polypropylene copolymer to fuse the tapes together in a subsequent consolidation process [22]. A significant advantage of tapes compared to more commonly used fibres is the more effective packing of such flat tapes, enabling higher reinforcement contents $(>80 \%)$ in the final product. These coextruded tapes can be used as unidirectional reinforcements in for example filament winding [23] or can be woven into fabrics, stacked and consolidated into flat laminates followed by shaping in a thermoforming process $[24,25]$. This process of tape coextrusion followed by hot-compaction in which these tapes are fused together has significant advantages over conventional manufacturing technologies for thermoplastic composites. Traditional manufacturing processes for thermoplastic composites rely on the impregnation of fibres with often highly viscous polymer resins. In the case of SRPs based on coextruded tapes, the matrix is coextruded simultaneously with the reinforcing phase of the tape and consolidation is achieved by 
a simple and fast welding or fusion process in which the matrix phase is selectively melted, thus completely removing impregnation problems as often encountered in traditional thermoplastic composite manufacturing.

Next to some of these manufacturing benefits, these materials have clear benefits from a circular economy and end-of-life point-of-view as a result of their mono-material character. Moreover, they are lightweight because (heavy) glass fibres are replaced by (lightweight) polymer fibres or tapes, and show competitive mechanical properties per unit weight, notably tensile strength and impact resistance, compared to traditional glass- or natural-fibre reinforced plastics $[4,26]$, partly due to their low density $\left(<1 \mathrm{~g} / \mathrm{cm}^{3}\right.$ for SRPP) and high reinforcement content ( $90 \%)$ compared to traditional composites $(40-60 \%)$.

Processing benefits as previously argued for short-fibre reinforced plastics do not necessarily apply for SRPs since current available commercial products like Curv ${ }^{\circledR}$, PURE ${ }^{\circledR}$ or Tegris $^{\circledR}$ are all based on continuous tape reinforced laminates, which do not allow for flow moulding processes. Moreover, the amount of matrix phase in these composites is minimum, limiting flow. Despite these limitations, there might however be an interest in developing discontinuous tape based SRPPs from a recycling point of view. At the moment, SRPP parts based on continuous reinforcements have to be recycled or better down-cycled by recompounding back into an extruder with complete loss of molecular orientation and properties of the reinforcing phase. However, particularly production waste like cuttings of fabrics or tapes could be chopped and used to make short tape SRPP composites, retaining some of the properties of these high strength tapes. The current paper reports on the property evaluation of such discontinuous tape SRPPs. For this, first model studies based on a single tape composites and cut or slitted fabrics were performed to assess the critical tape length for optimum stiffness and strength of SRPP composites based on aligned tapes. Both these experimental model studies were complemented by numerical studies using finite element analysis (FEA). Finally, the reinforcing potential of SRPP composites based on randomly oriented tapes are estimated based on finite element models using input data from the single tape model and discontinuous tape model composite studies.

\section{Experimental Methods}

\subsection{Specimen preparation}

\subsubsection{Single tape model composites}

The single tape model composites were composed of a single short PP tape ( $\left.L_{t}=40 \mathrm{~mm}\right)$ embedded in a PP copolymer matrix. Coextruded PP tape $(2.2 \mathrm{~mm}$ wide and $65 \mu \mathrm{m}$ thick) was provided by PURE Composites BV (Netherlands) and consisted of a homopolymer PP core (A) with a peak melting temperature of around $168^{\circ} \mathrm{C}$ and copolymer PP skins (B) with a melting temperature of around $135^{\circ} \mathrm{C}$. These PURE ${ }^{\circledR}$ tapes possess a Young's modulus of around $15 \mathrm{GPa}$ and a tensile strength of $500 \mathrm{MPa}$ (Table 1).

A co-extruded and oriented PURE ${ }^{\circledR}$ tape, of length equal to $40 \mathrm{~mm}$, was placed in the middle of 20 thin PP copolymer films (each $55 \mu \mathrm{m}$ thick). These films were made by compression moulding of random block copolymer PP pellets (Moplen Basell, 16\% ethylene, Mw $320 \mathrm{~kg} / \mathrm{mol}$, MFI $5.5 \mathrm{~g} / 10 \mathrm{~min}$ ) in a hot-press. In order to use Digital Image Correlation (DIC) for mapping the local strains in single tape model composites, a random black speckled pattern (Fig. 1) was spray painted on the surface of the 
Table 1 Properties of co-extruded PP tapes

\begin{tabular}{lll}
\hline & Neat Tape [7] & $\begin{array}{l}\text { After free anneal- } \\
\text { ing at 135-145 } \\
{[27]}\end{array}$ \\
\hline Width, $W_{t}[\mathrm{~mm}]$ & 2.2 & - \\
Thickness, $H_{t}[\mu \mathrm{m}]$ & 65 & - \\
Density, $\rho\left[\mathrm{g} \cdot \mathrm{cm}^{-3}\right]$ & 0.73 & - \\
Draw Ratio, $\lambda[-]$ & 17 & - \\
Composition, A:B:A [\%] & $5: 90: 5$ & - \\
Tensile Modulus, $E_{t, 11}[\mathrm{GPa}]$ & 15 & $9-11$ \\
Tensile Strength $\sigma_{t, 11}^{u}[\mathrm{MPa}]$ & 500 & 400 \\
Strain to Failure $[\%]$ & 7 & - \\
\hline
\end{tabular}

film in direct contact with the tape. In order to ensure that interfacial adhesion was not affected by the paint, the pattern was applied to the film surface that is not in direct contact with the tape, meaning that matrix deformation is measured at about $50 \mu \mathrm{m}$ (i.e. the film thickness) above the tape/matrix interface. The specimens were vacuum bagged at $1 \mathrm{bar}$ and $135^{\circ} \mathrm{C}$ [25]. This low pressure and temperature ensured that there was no matrix flow, as this would distort the speckle pattern in the mid-plane of the specimen.

Previous studies have, however, shown that depending on the temperature, unconstrained or free annealing can lead to significant chain relaxation, tape shrinkage and loss of mechanical properties [27]. On the other hand, no or limited loss of chain relaxation occurs if these oriented PP tapes are constrained during heating [28, 29]. Low pressure vacuum bag consolidation, however, has shown to be insufficient to prevent molecular relaxation through lateral constraining of the oriented tapes, meaning that property reduction is rather similar to unconstrained free annealing [8, 25]. Hence, tape properties after vacuum bag moulding are expected to be significantly lower than those listed in Table 1 for virgin tape. Based on previous studies, values of around 9-11 GPa for Young's modulus and $400 \mathrm{MPa}$ for tensile strength are more likely to be expected (see Table 1) [27].

Fig. 1 Tensile model composite specimen of a single tape embedded in a PP copolymer matrix. Note that the random black speckle pattern, for Digital Image Correlation (DIC), is positioned on top of the mid-plane film, 50 $\mu \mathrm{m}$ above the tape surface

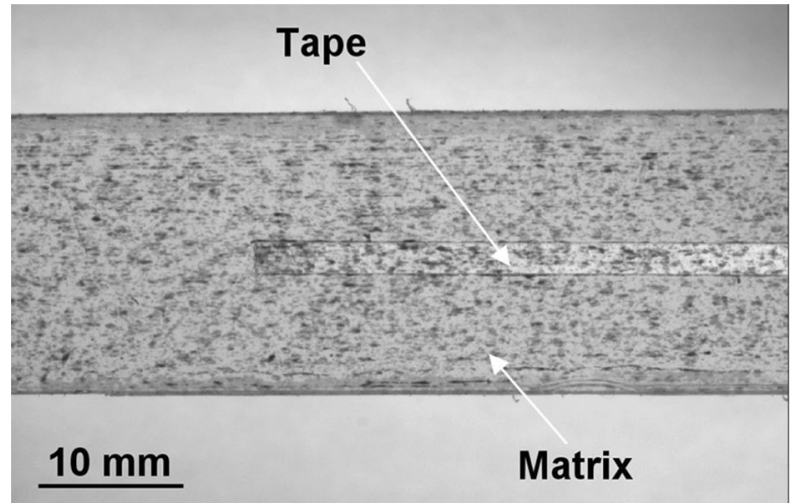




\subsubsection{Aligned discontinuous tape composites}

An aligned discontinuous tape model composite was manufactured from coextruded tape based plain weave fabrics. As mentioned earlier, due to the small amount (10\%) of copolymer matrix present in the PURE tapes, there is only very limited flow during the compaction process of SRPP composites. Hence, it is not straightforward to use flow based compression- or injection moulding processes. Instead, here aligned discontinuous tape composites were made by hot-pressing of slitted or pre-cut layers of plain weave PP tape fabrics (Fig. 2) at $145^{\circ} \mathrm{C}$ and 40 bar [7, 8, 22]. It has been shown that under these conditions, high lateral pressure constrains the tapes during heating, leading to limited property loss in the case of continuous tapes [7, 8]. However, in the case of short tapes, loss of molecular orientation and mechanical properties can be expected due to ineffective constraining of such cut tapes. These pre-cut SRPP laminates were composed of six layers of fabric by alternating stacking of layers 1 and 2 (see Fig. 2). After compression moulding, the non-slitted edges, which contained continuous tape for easy handling and assembling, were removed. The result was a regular aligned discontinuous tape composite, albeit with only $50 \%$ of the tapes aligned in the specimen direction, with a constant tape length, $l_{t}$, and an overlap length of $l_{t} / 2$. A total of six laminates were manufactured with pre-cut tape lengths of $8.8,13,18,20,30$ and $40 \mathrm{~mm}$.

\subsection{Mechanical testing}

\subsubsection{Stress transfer in single tape model composites}

The single tape model composites were tested in tension. Specimens were $20 \mathrm{~mm}$ in width and $1 \mathrm{~mm}$ thick. A gauge length of $100 \mathrm{~mm}$ and a cross-head speed of $1 \mathrm{~mm} / \mathrm{min}$ were used. The strain was measured using the ARAMIS Digital Image Correlation (DIC) System (GOM GmbH, Germany). A schematic of the test-setup is shown in Fig. 3. A twodimensional (2D) DIC analysis would in principle suffice for these planar single tape model composites. However, due to extensive plastic deformation of the PP copolymer, a three-dimensional (3D) analysis would yield more accurate in-plane measurements. The angle between the two cameras was $40^{\circ}$ and a calibration window of $25 \times 20 \mathrm{~mm}$ was used. Other DIC parameters included a subset of $15 \times 15$ pixels and a step size of 5 pixels. The data was solved using the multifacet matching option in order to get a higher accuracy. Around 2000 images were taken during a single test. Only a selection of them was

Fig. 2 Discontinuous aligned SRPP model composite specimen. A laminate pressed from alternating fabric layers 1 and 2 , leads to a regular discontinuous tape composite with a pre-cut tape length of $l_{t} / 2$. The specimens were tested in the direction of the black tapes

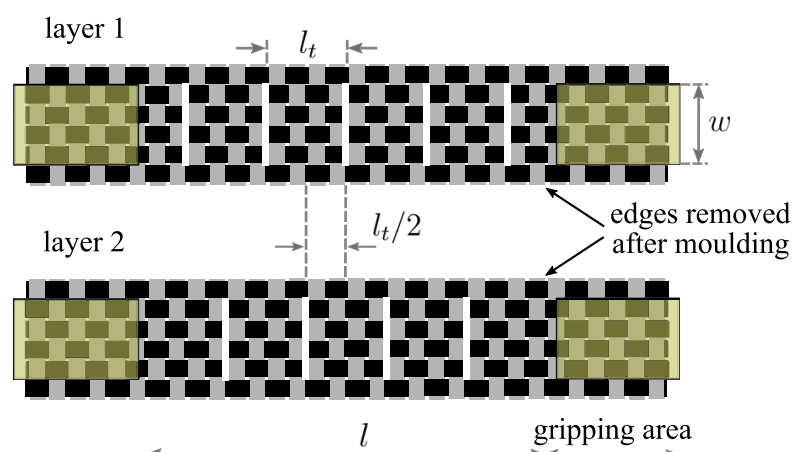


Fig. 3 Digital Image Correlation (DIC) strain mapping set-up for measuring matrix deformation during loading of a single tape model composite

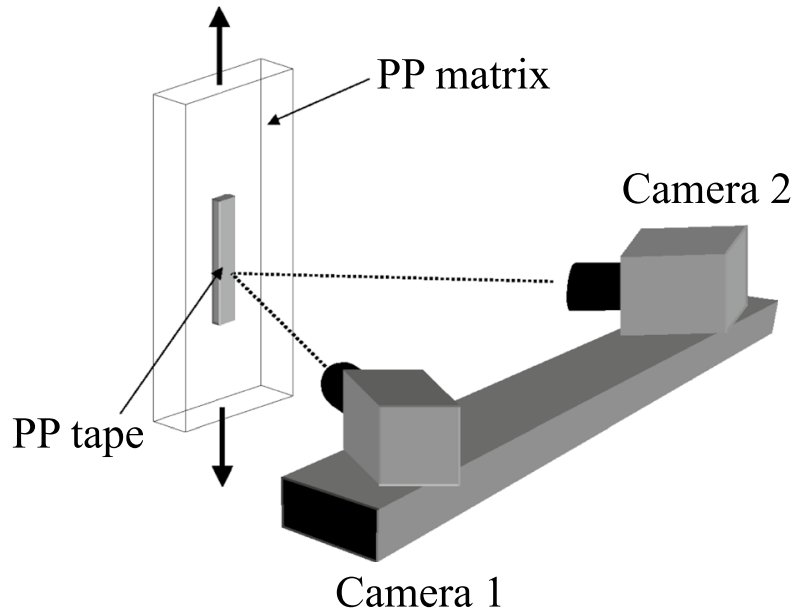

processed as computationally the multifacet option is time consuming. It should be noted that the definition of the shear strain measured by the ARAMIS DIC system is defined as the angle reduction / 2 .

\subsubsection{Aligned discontinuous tape composites}

The pre-cut SRPP laminates with cut intervals at 8.8, 13, 18, 20, 30 and $40 \mathrm{~mm}$ were tested in tension in a universal tensile machine (Instron 5584). The specimens composed of 6 layers of pre-cut fabric had a width, $w$, equal to $15 \mathrm{~mm}$ and a thickness, $t$, equal to $0.9 \mathrm{~mm}$. The gauge length, $l$, was $120 \mathrm{~mm}$ and the cross-head speed was $10 \mathrm{~mm} / \mathrm{min}$. The strain was measured by a clip-on extensometer (Instron 2620-602).

\section{Finite element modelling}

The primary aim of the finite element modelling (FEM) is to estimate the potential of SRPP composites based on aligned and randomly oriented short tapes. Several material properties are, however, not all that well defined e.g. the interfacial stress transfer between the tapes and the stiffness and strength of the tapes after moulding, primarily in the tape direction, as these properties are affected by constraining and process history [5, 27]. Thus, first the experiments of the single tape model composites are used to estimate the interface properties between the PP tape and PP copolymer described by a cohesive law. Then, the estimated cohesive law is used in modelling of the discontinuous aligned tape composites. Initial values for the material properties of the tapes after hot-compaction are taken from Alcock et al. [7] and then these values are slightly calibrated in order for the finite element predictions to agree well with the experimental data for pre-cut tape lengths equal to 40 $\mathrm{mm}$. Next, these finite element predictions are compared with the experimental data for other pre-cut tape lengths. Good agreement between finite element predictions and experimental data gives confidence that the properties of SRPP composites based on randomly oriented short tapes, for which there are no experimental data, can be relatively accurately predicted. 
The finite element models developed for the single tape model composites, aligned discontinuous tape composites and randomly oriented short tape composites involve strong non-linearities and convergence is difficult when implicit finite element methods are used. A number of numerical stability methods exist to overcome these difficulties, however an explicit finite element method is more robust [30]. Therefore, an explicit solver was used to solve the models under quasi-static conditions using mass-scaling [31]. It was ensured that the sum of the kinetic energy and the energy dissipated by viscosity (viscous damping in explicit solver) was less than $0.5 \%$ of the strain energy.

\subsection{Single tape composite}

In short fibre composites, the stress distribution in the vicinity of fibre ends is key to the understanding of the reinforcing mechanism of short or discontinuous fibres. Over the years various micromechanical models have been proposed to describe the load transfer phenomenon in composites. Some of the earliest models [32, 33] assume perfect bonding between fibre and matrix and either elastic or plastic behaviour of the matrix. Following this early work, numerous models have been developed which included additional failure phenomena such as debonding, partial debonding or local yielding [34-36]. All these models apply to circular fibre reinforcement rather than tapes but Hsueh [37, 38] did develop a two-dimensional elastic stress transfer model to analyse the mechanical properties of platelet or ribbon reinforced materials. However, most micromechanical models, except a few e.g. [39], cannot be used to predict interface damage initiation and propagation under loading. For this reason, here cohesive based finite element analysis was used to model and more importantly link the single tape composite behaviour with the discontinuous tape SRPP composites. In cohesive zone modelling, the fracture is described by a traction-separation law or a cohesive law $[40,41]$ and is implemented in a finite element.

\subsubsection{Geometry and boundary conditions}

Figure 4 shows the geometry of the 3D finite element model built in the commercial code Abaqus [42]. Due to symmetry only one sixth of the single tape composite (Fig. 1) was modelled. Symmetry conditions imply that the nodes at $x=-L_{t} / 2$ are constrained in the $x$-direction, the nodes at $y=0$ are constrained in the $y$-direction, and the nodes at $z=0$ are

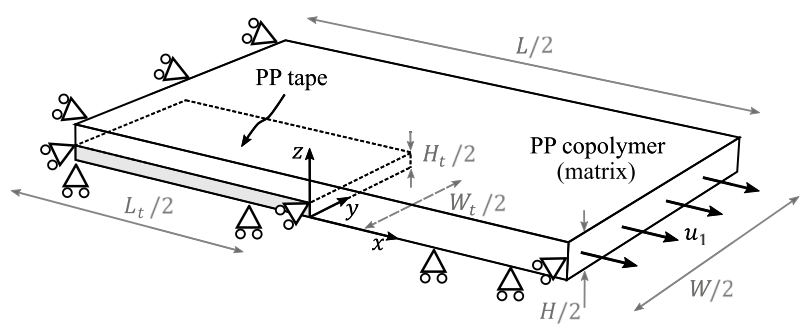

Fig. 4 Geometry and boundary conditions of the 3D finite element model for the stress transfer analysis of the single tape composites (Fig. 1). Due to symmetry, only $1 / 8$ of the specimen is modelled. The dimensions of the PP tape are: $L_{t} / 2=20 \mathrm{~mm}, H_{t} / 2=32.5 \mu \mathrm{m}$ and $W_{t}=1.1 \mathrm{~mm}$. The dimensions of the PP copolymer are: $L / 2=50 \mathrm{~mm}, H_{2}=0.55 \mathrm{~mm}$ and $W_{2}=10 \mathrm{~mm}$ 


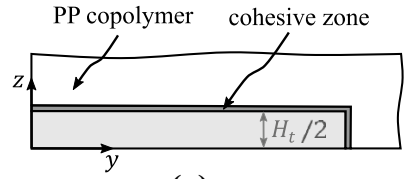

(a)

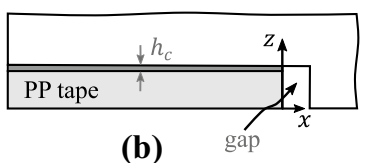

(b)

Fig. 5 Cross-sectional views of the single tape composite of Fig. 4, showing the details of the cohesive zone modelling: a) $x=0$ : cohesive elements are used to model the tape/interface along the width and thickness of the tape, b) $x=0$ and $z=0$ : A gap exists between the tape end and the PP matrix along the $y$-axis

constrained in the $z$-direction. The specimen is loaded in displacement control by applying displacements, along the $x$-direction, in the nodes at $x=L / 2$.

\subsubsection{Interface cohesive law}

Figure 5 shows schematically the 3D cohesive law inserted between the PP tape (reinforcement) and the PP copolymer (matrix) to model the tape/matrix interface. As can be seen, the cohesive zone has a small but finite thickness, $h_{c}$, equal to $1 / 10$ of $H_{t} / 2$. The in-plane length of the cohesive element is 10 times the thickness $h_{c}$ and it is small enough to have more than 8 cohesive elements with the fracture process zone [43]. A non-zero cohesive zone thickness was preferred to avoid interpenetration problems [44]. As can be seen from Fig. 5, the cohesive zone is between the entire tape/matrix interface except along the $y$-axis at $x=0$, where a gap exists between the PP tape and the PP copolymer. Initial simulations, including cohesive elements in this region, showed that the tape end debonds very early, as expected, from the matrix and has a negligible effect on the subsequent interface crack propagation. Thus, in order to avoid unnecessary numerical complexities, it was preferred to model the tape end as already debonded from the PP matrix. Based on initial simulations, the effect of interface friction was negligible and thus friction was not included in the mode II traction-separation law.

A cohesive law with linear softening was used to model the mode I and mode II traction-separation laws of the tape/matrix interface as shown in Fig. 6. It is assumed that the mode I and mode II components are identical and thus the mixed mode fracture is pathindependent [45]. It should be noted that the mode II (shear) component is predominant

Fig. 6 Mode I (interface) cohesive law with linear softening: the mode I (normal) peak traction, $\hat{\sigma}_{n}$, is attained at the normal opening $\delta_{n}^{o}$. The normal tractions decreases to zero at the critical normal opening $\delta_{n}^{f}$. The area under the traction-separation curve equals the mode I interfacial fracture energy $\Gamma_{n}$. The mode II (shear) cohesive law is identical to the mode I component: $\hat{\sigma}_{t}=\hat{\sigma}_{n}, \delta_{t}^{o}=\delta_{n}^{o}$ and $\Gamma_{t}=\Gamma_{n}$

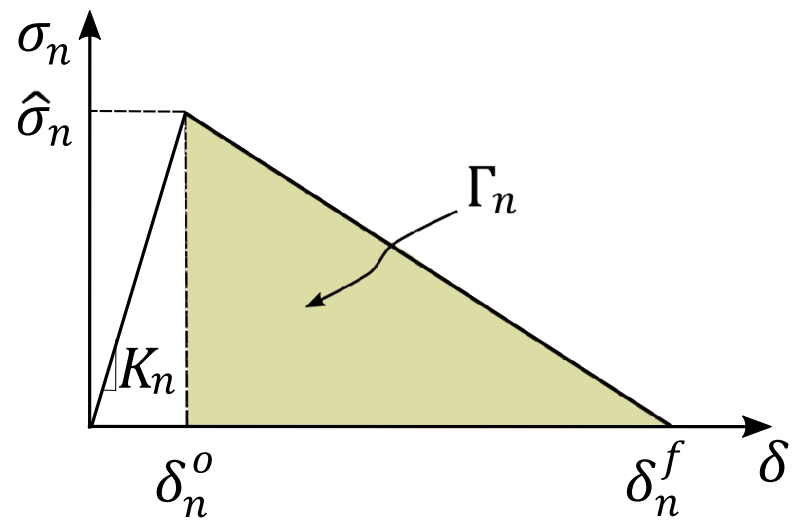


and thus the assumption of a cohesive law being independent of the mode mixity has a negligible effect on the results. The shape of the cohesive law (linear softening) has also a negligible effect since the length of the fracture process zone is small, e.g. the critical normal and tangential openings for complete interface separation are small (submicron scale). It should be noted that the interface cohesive law does not include the PP copolymer plastic deformation, which is taken into account by modelling the PP copolymer as elastic-plastic solid as described in Section 3.1.3. Critical parameters are the peak traction and fracture energy. These parameters are unknown and are estimated from the finite element simulations by comparing the results with the experimental data from the single tape model composites.

\subsubsection{Tape and PP copolymer properties}

The tape is modelled as an anisotropic linear elastic material with $E_{t, 11}=9 \mathrm{GPa}$ after annealing (see Table 1). It is assumed that the other elastic constants (e.g. shear, transverse modulus) are not greatly affected by the manufacturing process and are taken from Alcock et al. [7]. The PP copolymer is modelled as an elastic-plastic material using $J_{2}$ plasticity theory. The stress-strain curve is shown in Online Resource Fig. S1.

\subsection{Aligned Discontinuous tape composites}

Figure 7a shows an idealised 3D schematic illustration of a plain-weave SRPP composite (Fig. 2). The tape length and width, $\ell_{t}$, are approximately $2.5 \mathrm{~mm}$. Even for the smaller tape length, $l_{t}$, (Fig. 2) a 3D finite element model would be very large. Thus, for computational reasons, an approximate $2 \mathrm{D}$ finite element model representation was built from the actual 3D composite structure as shown in Fig. $7 \mathrm{~b}$.

\subsubsection{Geometry and boundary conditions}

The details of the finite element model of Fig. 7b are shown in Fig. 8. The tapes are modelled as anisotropic elastic solids and the material orientation follows the tapes orientation. As mentioned above, the 2D finite element model is an idealised approximation e.g. there is no variation in the orientation of the tapes as observed by Alcock et al. [8] and $\theta$

Fig. 7 a) Idealised 3D plainweave SRPP composite: the tape length and width is $\ell_{t}$ and b) $2 \mathrm{D}$ approximation of the $3 \mathrm{D}$ plain weave tape structure

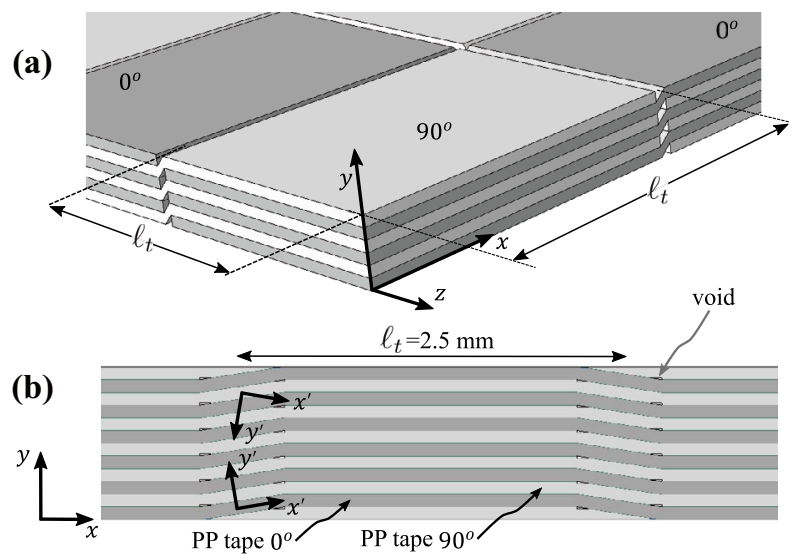




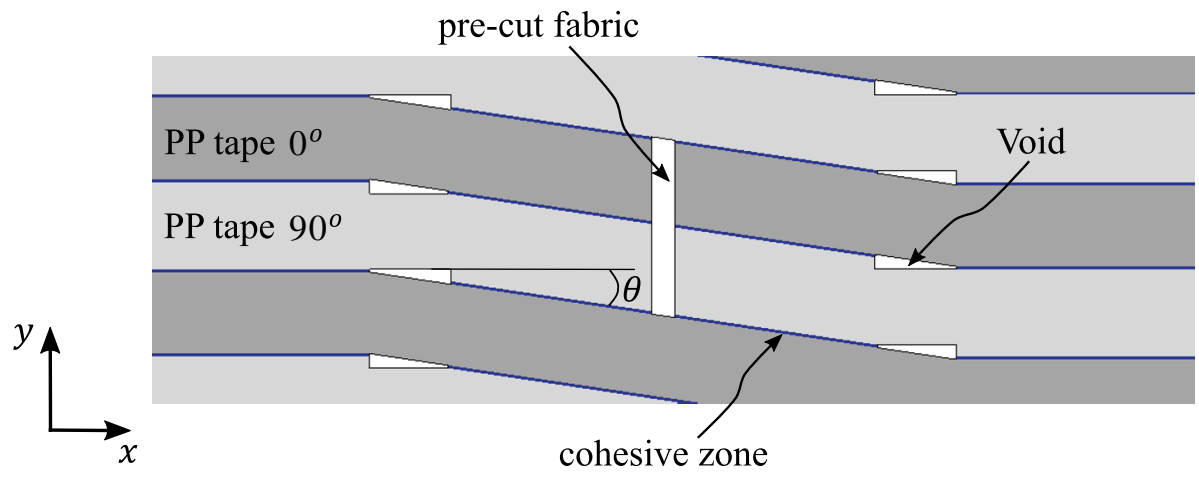

Fig. 8 Details of the 2D finite element model (Fig. 7) showing: the cohesive zones between the tapes, a precut fabric $\left(0^{\circ}\right.$ and $90^{\circ}$ oriented tapes $)$ and the voids between the tapes originating from the hot compaction

is constant and equal to $8.5^{\circ}$. Alcock et al. [8] reported a significant presence of inter-tape (or interply) voids for low consolidation temperatures and pressures during manufacturing of woven fabric based SRPP's, which potentially may have some effect on the composite strength. Such voids are included in the finite element model as shown in Fig. 8. However, a comparison with models without voids showed only a minor effect on composite strength and thus the inclusion or not of the voids did not significantly influence the reported results. This is also in agreement with experimental findings by Deng et al. [46]. Cohesive zones are inserted between all tapes along the entire specimen length. Similar to the single tape finite element model, the cohesive elements have a finite thickness, $h_{c}$, equal to $2.5 \mu \mathrm{m}$ and a length equal to $10 \mu \mathrm{m}$. The average length of the plane strain reduced integration elements used to model the tapes is also $10 \mu \mathrm{m}$.

All the nodes at $x=0$ are constrained in the $x$-direction and the node $x=0$ and $y=0$ is also constrained in the $y$-direction. Non-zero nodal displacements are applied, in $x$-direction, to the nodes at $x=l$. The thickness of the discontinuous tapes, $h_{t}$, is equal to $H_{t}$ (Table 1).

\subsubsection{Cohesive zone and tape properties}

The cohesive law parameters are taken from Section 3.1 e.g. the single tape model experiments and simulations were used to extract the cohesive law for the modelling of the aligned discontinuous tape composites. The Hashin anisotropic damage model [47, 48] as implemented in Abaqus [42] was used to model failure of the tapes. Because of the complex geometry, particular in regions where tapes are misaligned with respect to the global coordinate system, tape strength values should be defined in all directions and not only along the tape axis (see Table 1).

\subsection{Randomly oriented short tape composites}

SRPP composites based on randomly oriented short tapes are a collection of tapes of length, $l_{t}$, width $w_{t}$ and height, $h_{t}$, with random in-plane orientation. Within each short discontinuous tape, the material orientation is constant and thus these composites present many similarities to randomly oriented strand (ROS) composites [49, 50]. Three dimensional numerical models have been recently developed to model such composites by taking 
Table 2 Elastic constants of co-extruded PP tapes and strength values for modelling the discontinuous aligned tape composites

Elastic constants [7]

\begin{tabular}{lllllllll}
\hline$E_{t, 11}$ & $E_{t, 22}$ & $E_{t, 33}$ & $v_{t, 12}$ & $v_{t, 13}$ & $v_{t, 23}$ & $G_{t, 12}$ & $G_{t, 13}$ & $G_{t, 23}$ \\
{$[\mathrm{GPa}]$} & {$[\mathrm{GPa}]$} & {$[\mathrm{GPa}]$} & {$[\mathrm{GPa}]$} & {$[\mathrm{GPa}]$} & {$[\mathrm{GPa}]$} & {$[\mathrm{GPa}]$} & {$[\mathrm{GPa}]$} & {$[\mathrm{GPa}]$} \\
$9.0-11.0$ & 1.1 & 1.1 & 0.2 & 0.25 & 0.25 & 0.9 & 0.9 & 0.9 \\
\hline \multicolumn{2}{l}{$\begin{array}{llll}\text { Strength values }[7] \\
\sigma_{t, 11}^{u}\end{array}$} & $\sigma_{t, 11}^{c, u}$ & $\sigma_{t, 22}^{u}$ & $\sigma_{t, 22}^{c, u}$ & $\sigma_{t, 12}^{u}$ & $\sigma_{t, 23}^{u}$ & & \\
{$[\mathrm{MPa}]$} & {$[\mathrm{MPa}]$} & {$[\mathrm{MPa}]$} & {$[\mathrm{MPa}]$} & {$[\mathrm{MPa}]$} & {$[\mathrm{MPa}]$} & & & \\
$400.0[27]$ & 40.0 & 35.0 & 80.0 & 35.0 & 35.0 & & & $\mathrm{a}$ \\
\hline
\end{tabular}

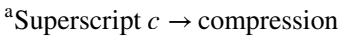

${ }^{b}$ After failure, at a material point, material stiffness decreases to zero, leading to material failure. The energy dissipation during this progressive damage process is $10 \mathrm{~kJ} / \mathrm{m}^{2}$ for all damage modes

into account their meso-structure [51]. In the present study, an earlier approach by Selezneva et al. [52] was preferred. First, since it is computationally more efficient and secondly, because a 3D distribution of the tapes is not available. The 2D approach of Selezneva et al. [52] accounts for local meso-structural effects and was used to create the finite element models (see Fig. 9) for the prediction of the stiffness and strength of SRPP composites based on randomly oriented short tapes. As can be seen in Fig. 9 all the short tapes are planar aligned e.g. there are no folds or bends and thus the predictions should be considered as an upper bound of stiffness and strength. Selezneva et al. [52] used an analytical approach to predict the stiffness and strength of a composite similar to Fig. 9. Here, a cohesive based finite element model was used by inserting cohesive zones between the tapes along the $x$-axis to account for interfacial debonding. Cohesive law parameters from the single tape model composites were used. The tapes were modelled as an anisotropic material with properties defined from the experiments and analysis of discontinuous tape composites (see Table 2). Tape failure is modelled by using the Hashin damage model (see Section 3.2.2). The thickness of the short tapes, $h_{t}$, is equal to $H_{t}$ (Table 1 ).

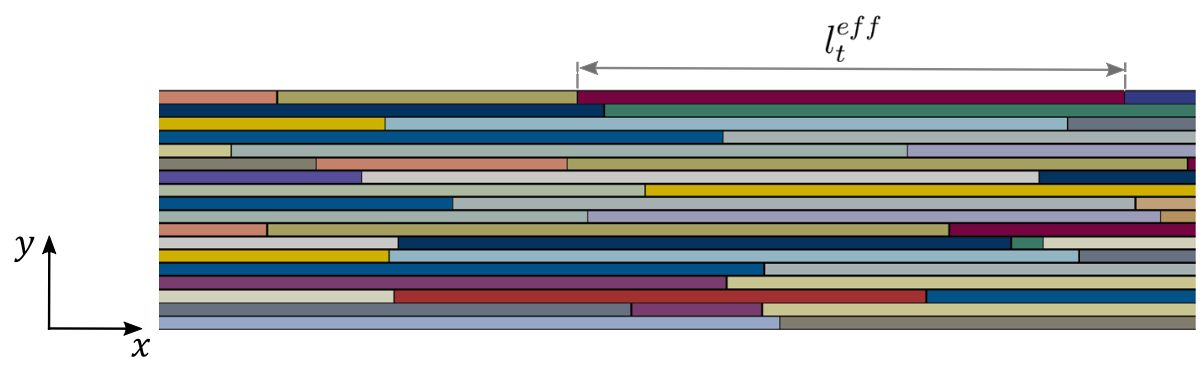

Fig. 9 Partial view of the 2D finite element model for randomly oriented short tape PP composites: The effective tape length $l_{t}^{\text {eff }}$ depends on the tape orientation and cut location (along $z$-axis). Cohesive elements are inserted between the tapes along the $x$-axis. Tape ends are not connected with each other 
Fig. 10 View of a cut tape oriented at an angle $\phi$, with respect to the global coordinate system $(x, y, z)$. The effective tape length, $l_{t}^{\text {eff }}$, for a 2D model, depends both on $\phi$ and the distance $\Delta_{z}$, which is the cut location

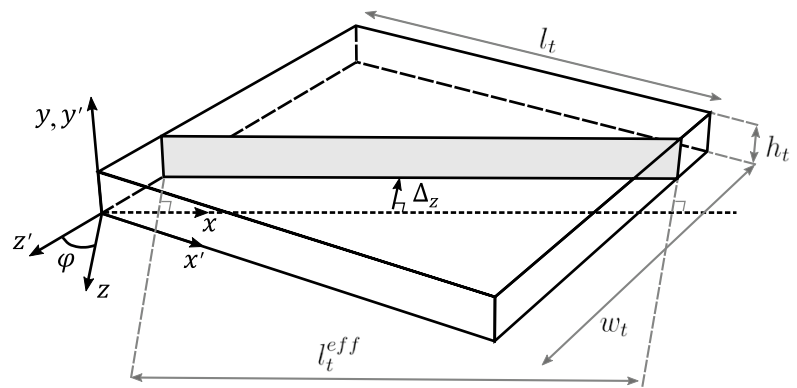

The effective length, $l_{t}^{\text {eff }}$, of each tape in Fig. 9 depends both on the orientation of the tape and the cut location to create a $2 \mathrm{D}$ representation of the $3 \mathrm{D}$ structure. The effective length, defined in Fig. 10, is given by [52]:

$$
l_{t}^{e f f}=\min \left(l_{t}^{\text {eff } \mid \max } \frac{\Delta z}{\dot{z}}, l_{t}^{\text {eff } \mid \max }\right)
$$

where

$$
l_{t}^{e f f \mid \max }=\min \left(\frac{l_{t}}{\cos \phi}, \frac{w_{t}}{\sin \phi}\right)
$$

and

$$
\dot{z}=\min \left(l_{t} \sin \phi, w_{t} \cos \phi\right)
$$

Similar to [52], the ends of the tapes are not connected and stresses are transferred through the cohesive zone.

\subsection{Analytical expressions for Young's modulus and strength}

Several analytical models have been developed for the predictions of stiffness and strength of discontinuous fibre composites [53]. These composites are, however, different from the aligned discontinuous tape composites and the SRPP composites based on randomly oriented short tapes as studied in the present work and are more closely related to randomly oriented strands (ROS) composites. For comparison purposes, a basic analytical model for discontinuous composites, the modified rule of mixtures, is included in the present work. The Young's modulus of the composite is given by:

$$
E_{c}=\chi_{L} \chi_{o} E_{t, 11} V_{t}+E_{m}\left(1-V_{t}\right)
$$

where $\chi_{L}$ and $\chi_{o}$ are the efficiency factors related to fibre (or tape) orientation and length. $V_{t}$ is the tape volume fraction and $E_{m}$ represents the Young's modulus of the matrix. The composite strength is:

$$
\sigma_{c}=\chi_{L} \chi_{o} \sigma_{t, 11}^{u} V_{t}+\sigma_{m}^{y}\left(1-V_{t}\right)
$$

where $\sigma_{m}^{y}$ is the yield stress of the matrix. The efficiency factor $\chi_{o}$ is equal to 0.5 for the discontinuous aligned tape composites. For SRPP composites based on in-plane randomly 
oriented disconntinuous tapes $\chi_{o}=0.375$. For both composites, $V_{t}$ is equal to $90 \%$. The expression for the efficiency factor $\chi_{L}$ is [33]:

$$
\chi_{L}= \begin{cases}\frac{l_{t} \hat{\sigma}_{t}}{\sigma_{t, 11}^{u} h_{t}} & l_{t}<\frac{\sigma_{t, 11}^{u} h_{t}}{2 \hat{\sigma}_{t}} \\ 1-\frac{\sigma_{t, 11}^{u} h_{t}}{4 l_{t} \hat{\sigma}_{t}} & l_{t} \geq \frac{\sigma_{t, 11}^{u} h_{t}}{2 \hat{\sigma}_{t}}\end{cases}
$$

\section{Results \& Discussion}

\subsection{Single tape model composites}

\subsubsection{Stress transfer and debonding}

The evolution of the micromechanical deformation was studied as a function of the applied stress. Four different stress levels $(4.5,11.0,12.5$, and 13.7 MPa) were selected for this purpose as shown in Fig. 11. Two stress levels (a) and (b) were selected before initiation of debonding near the tape end based on the deformation at a distance $50 \mu \mathrm{m}$ away from the tape surface, (c) just after initiation of debonding and (d) after complete debonding along the tape/matrix interface. Three different sections $\left(x-x^{\prime}, A-A^{\prime}\right.$ and $\left.B-B^{\prime}\right)$ were selected parallel to the $x$-axis. The $x-x^{\prime}$ section of the strain $x$ coincides with the $x$-axis, i.e. passes through the centre of the tape (Fig. 12a) while the sections A-A and B-B run along the tape/matrix interfaces in order to characterise the interfacial shear strain (Fig. 12b). $A-A^{\prime}$

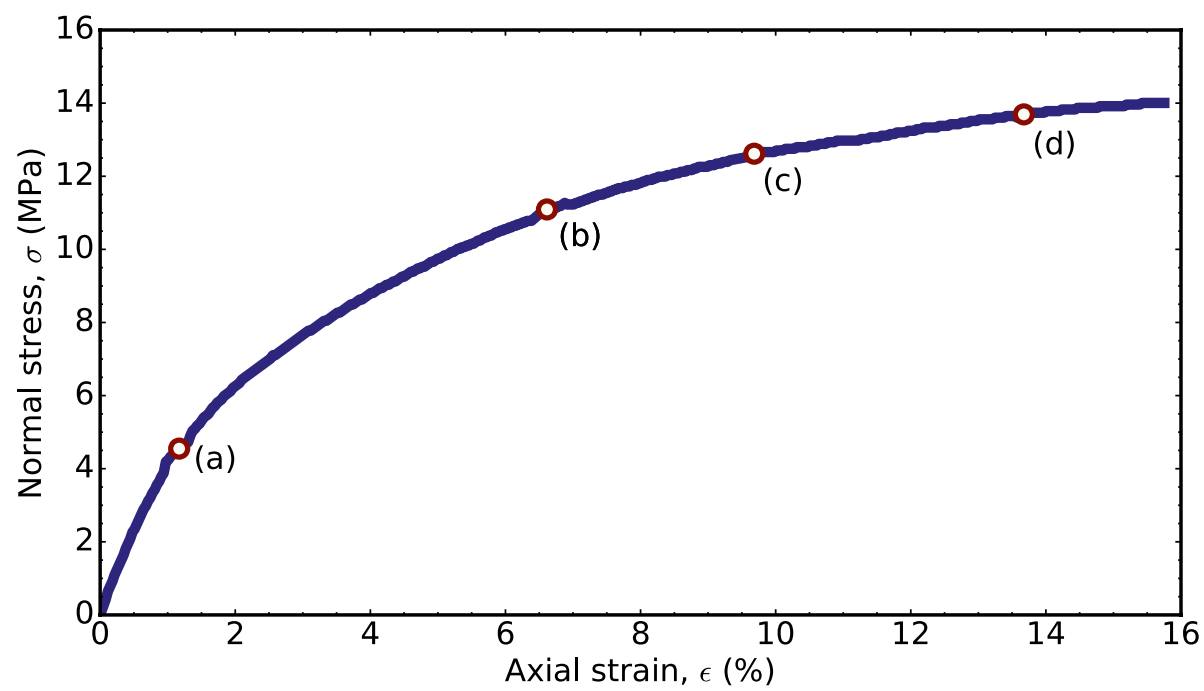

Fig. 11 Stress-strain curve of single PP tape model composite. The circle symbols represent the different stress levels analysed in Fig. 12 by DIC. Stress levels (a) and (b) represent loadings before the initiation of interface failure or debonding near the tape end, (c) just after initiation of debonding and (d) after complete debonding along the tape/matrix interface 
(a)

Strain $\mathrm{X}$

(Technical \%)
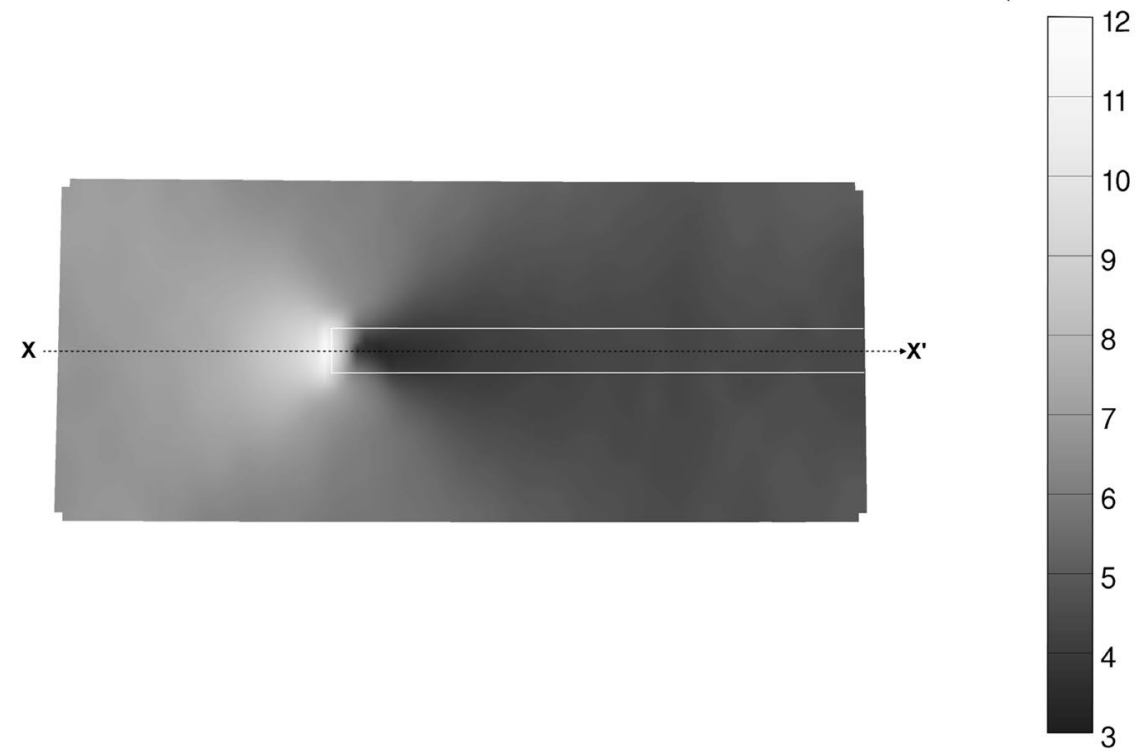

(b)

Shear strain $\left({ }^{\circ} \mathrm{DEG}\right)$
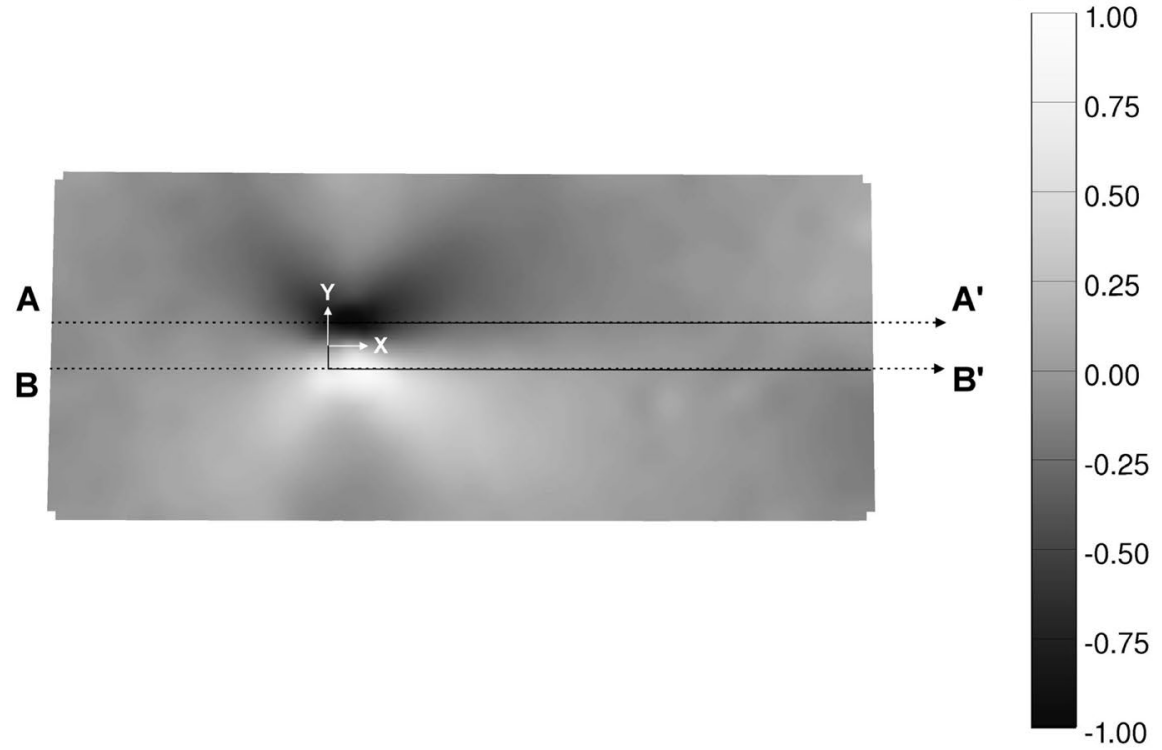

Fig. 12 Strain distribution in single PP tape model composites. A uniaxial stress of $12.1 \mathrm{MPa}$ is applied in the $x-x^{\prime}$ direction along the tape length. (a) Matrix tensile strain distribution. Note the very high strains $(>12 \%)$ at the tape end (light shades). Tape contour is indicated by the white lines. (b) Matrix shear strain distribution. Note the large shear strain area at the tape end (light and dark shades). Tape contour is here indicated by the black lines 
exhibits negative shear deformation and $B-B^{\prime}$ positive shear deformation in the local coordinate system.

Figure 12a shows the longitudinal (in tape direction) strain distribution in the matrix when the applied stress is equal to $12.1 \mathrm{MPa}$ (see Fig. 11). As mentioned before, the strain was measured in a plane about $50 \mu \mathrm{m}$ above the tape/matrix interface near the mid-plane. As expected, the highest strains are observed at the tape end, while the matrix above the tape (on the right side of the image) exhibits the lowest strain due to the stiffening effect by the oriented PP tape. In Fig. 12b, the shear strain distribution is plotted for the same stress level. Here, the strain scale is centred around zero with both light and dark areas representing high shear deformations. Shear deformation initiates near the tape end and the deformed area is symmetrical in relation to the tapes axis. The butterfly shape at $45^{\circ}$ with the $x$-axis is characteristic of shear deformations.

Figure 12 corresponds to strain distributions just before debonding at the tape end. The strain in the matrix away from the tape end is homogeneous across the width of the specimen (see Fig. 12a). In addition, because interfacial shear stresses in that region are zero (see Fig. 12b), the strains in the matrix and tape can be assumed equal. The average value of the strain in the shear free zone, is $4.5 \%$. The strain to failure of the tape is around 6\%. The stress in the tape at $4.5 \%$ strain is about $400 \mathrm{MPa}$ and close to the tensile strength of the tape. No tape failure was observed in any of the specimens although

Fig. 13 Matrix normal strain along $x-x^{\prime}$ section (see Fig. 12a) at different stress levels. Positive $x$-coordinates are along the tape/matrix interface (the tape end is at $x=0$ ). Between step (b) and (c), the tape end debonds $(x=0)$. Note that in load step (d), the strain between $x=0$ and 20 $\mathrm{mm}$ is higher due to extensive debonding along the interface (see Fig. 11)
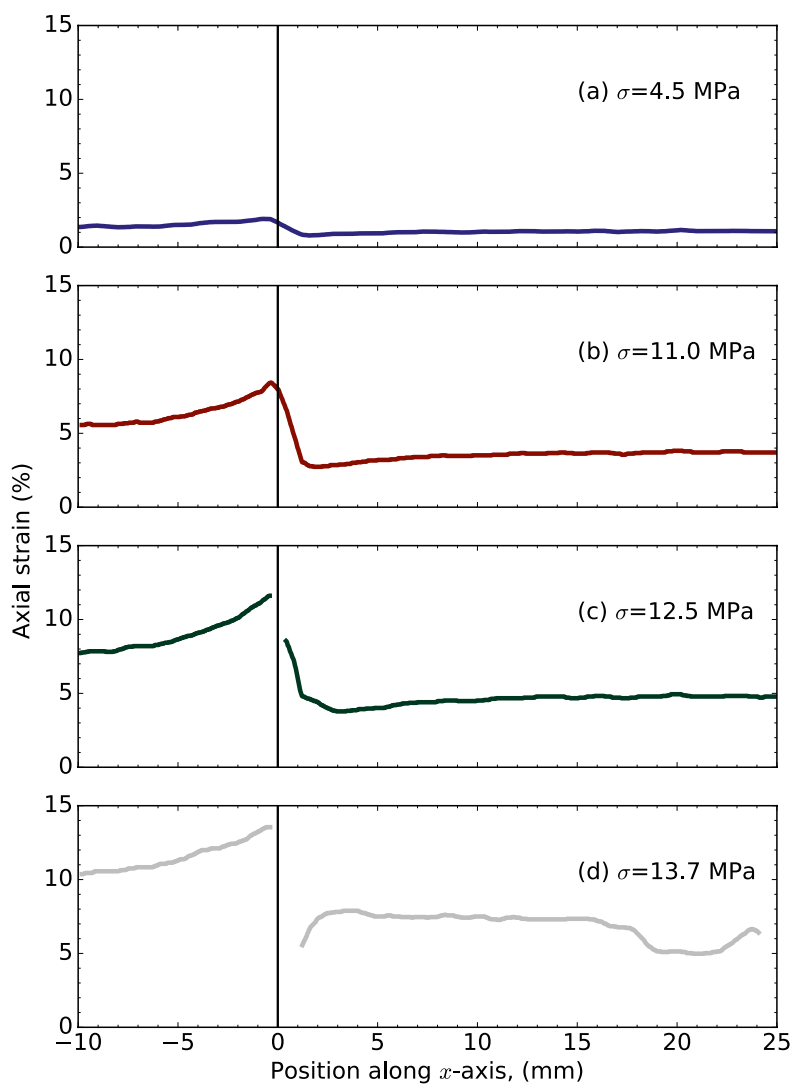
Fig. 14 Shear strain distribution along sections $A-A^{\prime}$ and $B-B^{\prime}$ (Fig. 12b) at different stress levels. Positive $x$-coordinates are along the tape/matrix interface (the tape end is at $x=0$ ). Between step (b) and (c), the tape end debonds and the shear profiles are no longer symmetric. Load step (d) corresponds to complete debonding of the interface (see Figure Fig. 11)
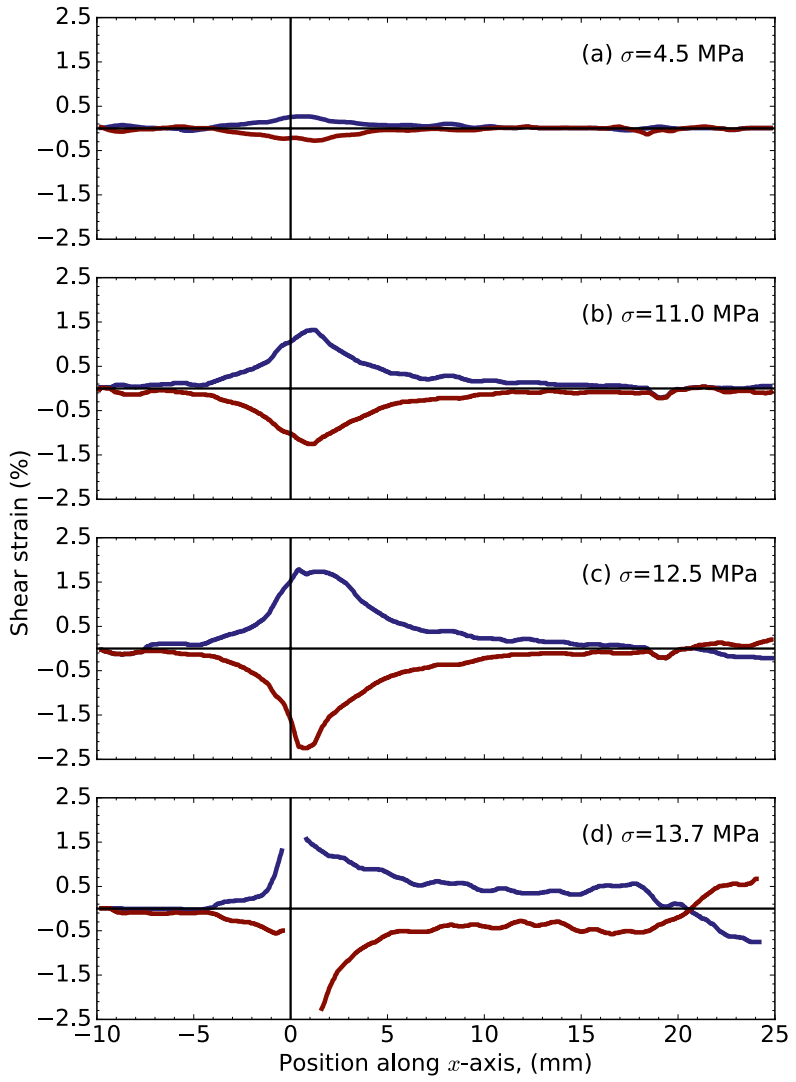

$85 \%$ of the tape tensile strength is reached in the centre of the tape before any damage or debonding occurs at the interface.

From the DIC contour plots (Fig. 12), the axial and shear strains along sections $x-x^{\prime}$ and $A-A^{\prime}, B-B^{\prime}$ are extracted and plotted in Figs. 13 and 14, respectively. The "macroscopic" interfacial shear stress transfer length runs up to $x=10 \mathrm{~mm}$ although the shear stress significantly decreases above $x=5 \mathrm{~mm}$ (Fig. 14b). In Fig. 13c the lack of data around $x=0 \mathrm{~mm}$ is probably due to the initiation of debonding at the tape end. The value of the strain in the matrix just before debonding is about $12 \%$, which compares well with the yield strain of the copolymer $\left(\epsilon_{\text {yield }}=15 \%\right.$ at a strain rate of $1 \% / \mathrm{min}$ [54]). In Fig. 14c, the shear deformation profiles along both interfaces are no longer symmetric because the load is not evenly distributed between the two interfaces as the tape end is not yet completely debonded. In Fig. 14d, the shear profile along both interfaces supports the idea that the tape has now fully debonded, the shear strains along sections $A-A^{\prime}$ and $B-B^{\prime}$ are non-zero along the tape length and change sign at exactly $x=20 \mathrm{~mm}$, i.e. the mid-section of the tape. The lack of available DIC data in the vicinity of the tape end, indicative of very large deformations, agrees well with visual post-examination of the specimen of a gap (opening) between tape end and matrix of 2-3 mm. At this stress level the load is no longer carried by the tape. Here, the load is now carried by the matrix only. 

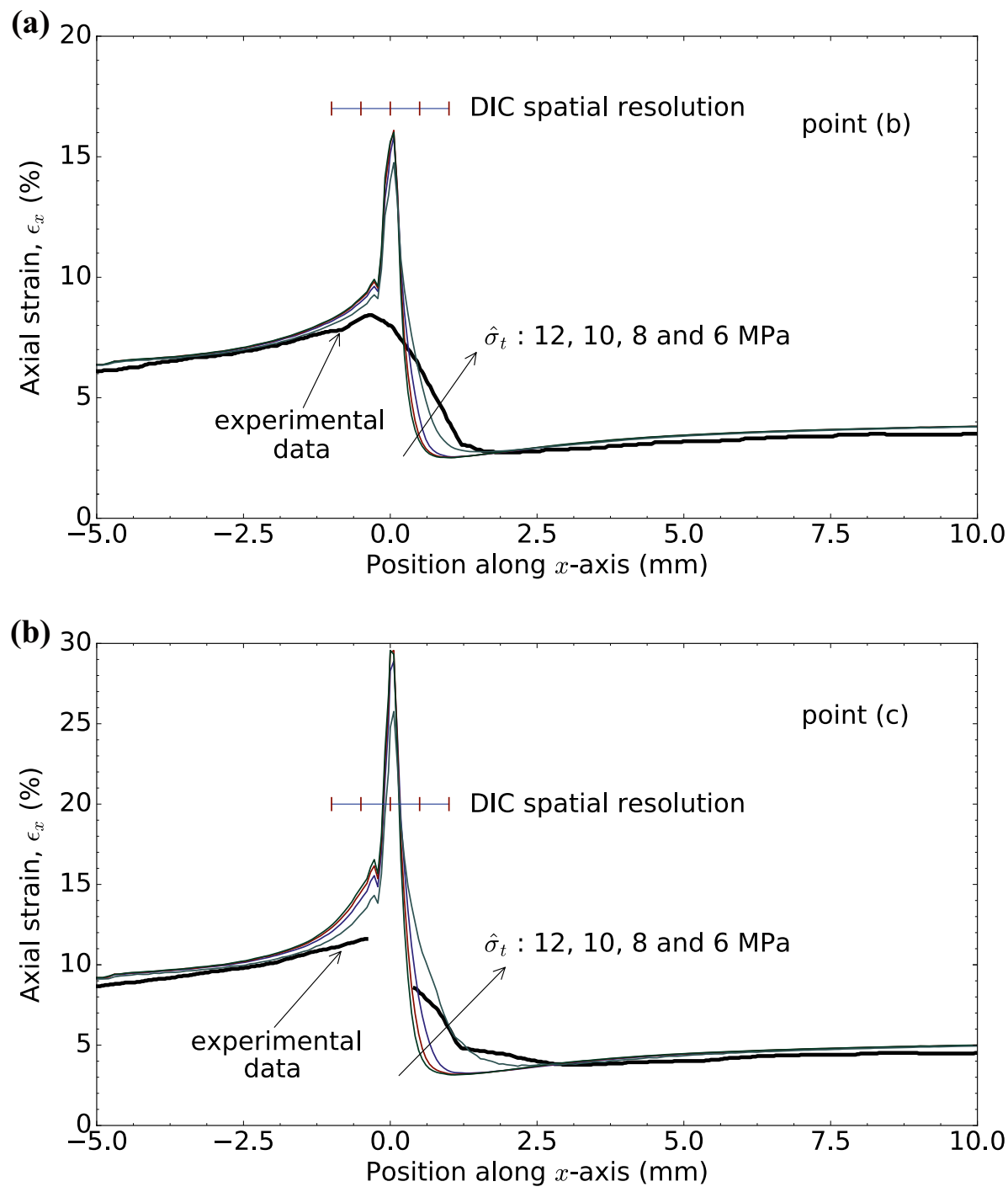

Fig. 15 Comparison of the finite element predicted axial strain, $\epsilon_{x}$, along section $x-x^{\prime}$ with the strains experimentally measured by DIC (see Figs. 13b and 13c) for the stress levels (b) and (c) (Fig. 11) for four different cohesive peak tractions $\hat{\sigma}_{t}$. The interface fracture energy, $\Gamma_{t}$, is equal to $1 \mathrm{~N} / \mathrm{mm}$ for all cases

\subsubsection{Estimation of the interface cohesive law by cohesive zone modelling}

Figure 15 shows the finite element predicted axial strains at a distance $50 \mu \mathrm{m}$ above the interface for two stress levels. For comparison reasons, the DIC measured strains (Figs. 13b and $13 \mathrm{c}$ ) are included. The mode II cohesive peak traction is varied while the interface fracture energy, $\Gamma_{t}$ is kept constant in order to estimate the interface strength. In Fig. 15, the spatial resolution of the DIC measurements is plotted and it is shown that it is rather coarse. Thus, it is expected that DIC cannot accurately capture the local strain variation in 


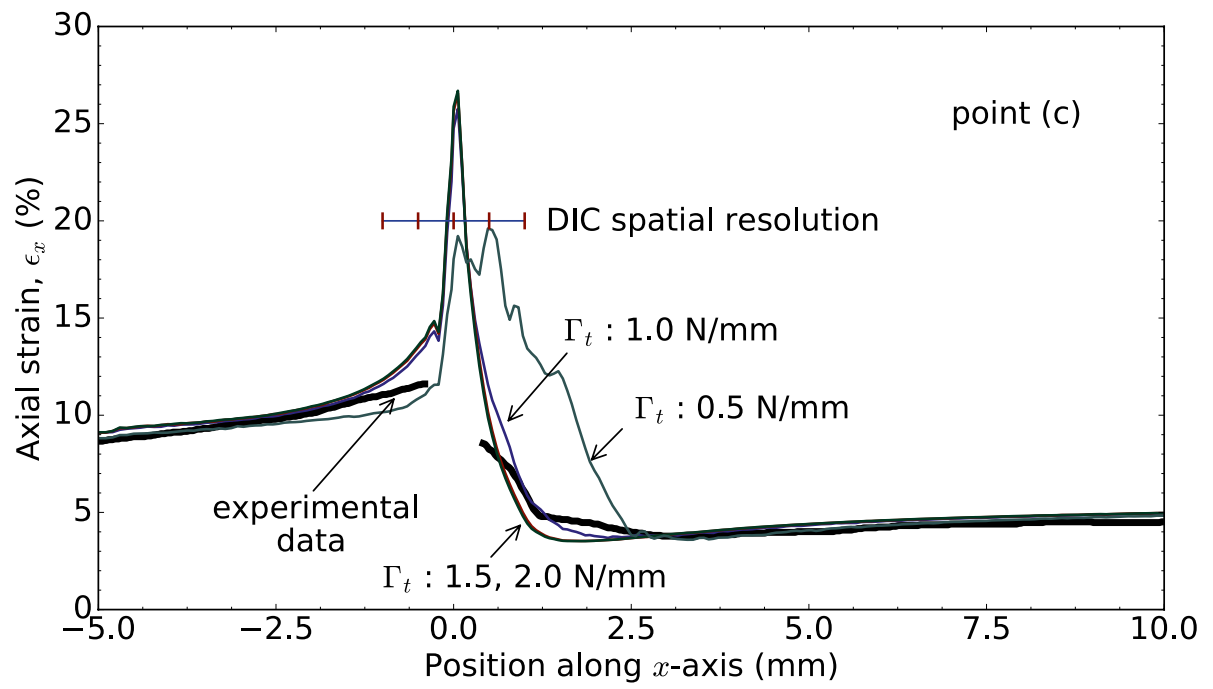

Fig. 16 Predicted axial strain, $\epsilon_{x}$, along section $x-x^{\prime}$ (see Fig. 13c) for the stress level (c) for four different fracture energies, $\Gamma_{t}$. The mode II cohesive peak traction, $\hat{\sigma}_{t}$, is equal to $6 \mathrm{MPa}$ for all cases

the region of the tape end. Therefore, to calibrate the interface cohesive law, the cohesive law parameters (peak traction and openings, see Fig. 6) were first chosen by comparing the finite element predictions with the experimental data away from the tape end. Once the initial values were determined, sensitivity studies were performed to select the cohesive law parameters that agree best with the experimental data i.e. peak traction variation in Fig. 15

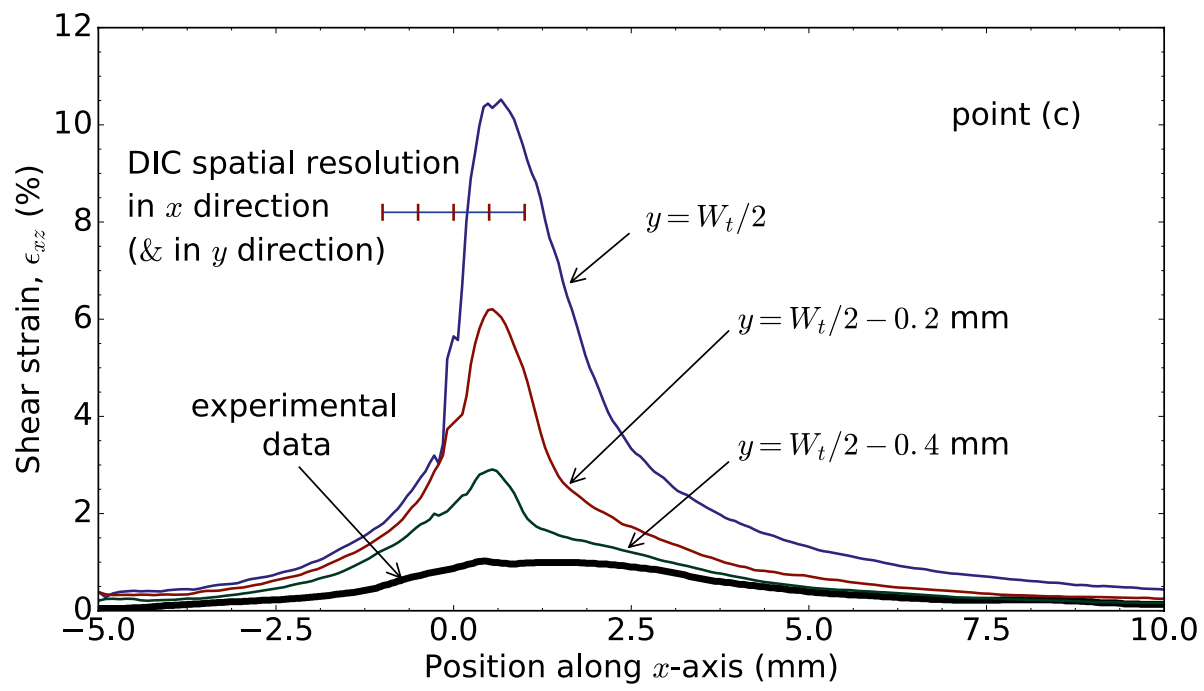

Fig. 17 Predicted shear strains, $\epsilon_{x z}$, along section $A-A^{\prime}$ (see 12b) at different positions along $y$-axis. The cohesive peak traction, $\hat{\sigma}_{t}$, is equal to $6 \mathrm{MPa}$ and the interface fracture energy, $\Gamma_{t}$, equal to $1 \mathrm{~N} / \mathrm{mm}$. The stress level corresponds to point (c) in Fig. 11 
and interface energy in Fig. 16. As can be seen from Fig. 15, interface peak tractions in the range of 6 to $12 \mathrm{MPa}$ are good estimates for the interface peak traction with a value of 6 MPa being closer to the experimental data.

As mentioned above, Fig. 16 shows the effect of the interfacial fracture energy for a constant peak traction $\hat{\sigma}_{t}$ equal to $6 \mathrm{MPa}$ for stress level (c) (Fig. 11). From, these results, it is estimated that a value of $1 \mathrm{~N} / \mathrm{mm}$ gives a relatively accurate value for the interfacial fracture energy. For lower values of $\Gamma_{t}$, extensive debonding was observed at this stress level in disagreement with the experimental observations.

Figure 17 is a similar plot to Fig. $15 \mathrm{~b}$ but instead of the axial strain, the finite element predictions of the shear strains are compared with the experimentally measured shear strains. It should be noted that because of the specific location of section $A-A^{\prime}$, a strong variation of the shear strains is expected both along $x$ and $y$-axes. The finite element predicted shear strains show this variation, three shear strain profiles are plotted along the $y$-axis (at the interface and slightly above the tape). The experimental values are, however, lower than the finite element predictions. As mentioned above, the spatial resolution of the DIC measurements is rather low and for the shear strains, averaging is performed along both $x$ and $y$-axes resulting in significant smoothing of the data. Therefore, the shear strain profiles from DIC were not used to further calibrate the interface cohesive laws.

The experimental measurements and visual observations on debonding initiation are based on measurements away from the interface. The contour plots of Fig. 18 shows the interface status at the tape end for the stress level (b) for which, based on DIC measurements, there is not interface debonding. As can be seen, for all three peak tractions, interface debonding has initiated but cannot be detected by DIC because of the distance between the interface plane and the measurements' plane. As expected a lower peak traction leads to interface debonding at lower applied stress or a longer debonded zone at the same stress level (Fig. 18). The difference in debonded length with varying peak traction is larger than one would expect from Fig. 15. This can be again explained by recognising that the measurements were taken slightly away from the actual interface.

A mode II peak cohesive traction, $\hat{\sigma}_{t}$, in the range of $6 \mathrm{MPa}$ is similar to that of glass fibre in polypropylene, which varies from 3 to $10 \mathrm{MPa}$ depending on the PP grade, glass fibre sizing, or experimental method used [55-57] and is in agreement with the shear strength of unidirectional SRPP composites [7]. The interface fracture energy used, being in the range $0.5-2.0 \mathrm{~N} / \mathrm{mm}$, is of the same order as the fracture energies reported by Sims [58] and Mahajan et al. [59] and slightly lower than the values reported by Alcock [54], which are in the range of $2.0 \mathrm{~N} / \mathrm{mm}$. It should be emphasized that the extracted cohesive

Fig. 18 Contour plots of the cohesive fracture criterion (interface crack debonding initiation) for the stress level (b) (see Fig. 11). The mode II cohesive peak traction, $\hat{\sigma}_{t}$, is: (a) $6 \mathrm{MPa}$, (b) $8 \mathrm{MPa}$ and (c) $10 \mathrm{MPa}$. The interface fracture energy, $\Gamma_{t}$, is equal to $1 \mathrm{~N} / \mathrm{mm}$ for all cases. $<1$ : no interface debonding, $1 \rightarrow$ interface shear stress reached $\hat{\sigma}_{t}$ (a)

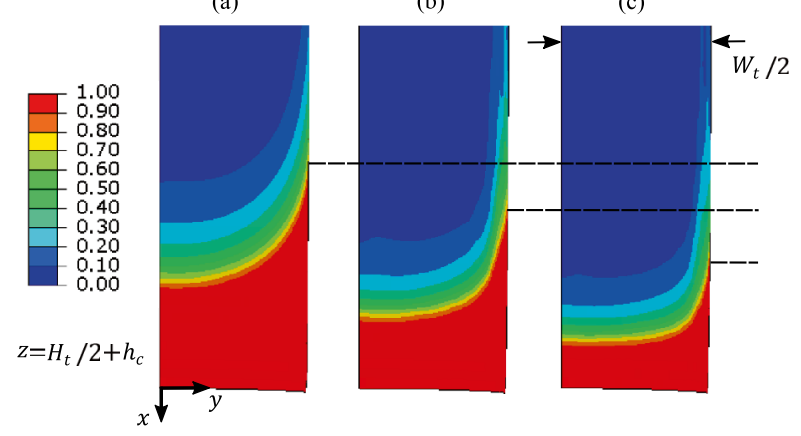




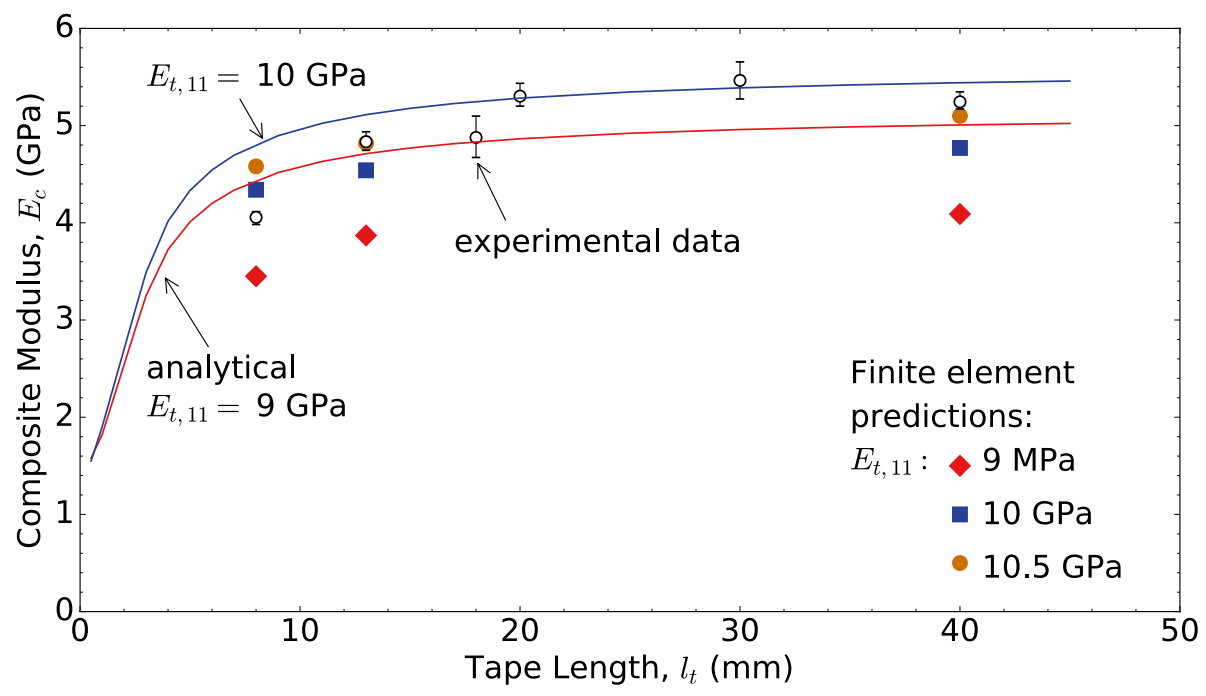

Fig. 19 Comparison of the finite element predictions for the Young's modulus of the aligned discontinuous SRPP composites as a function of tape length and three different tape Young's moduli, $E_{t, 11}$, together with experimental data. The analytical predictions using Eq. 4, with $\sigma_{t, 11}^{u}=400 \mathrm{MPa}$, are also included. The cohesive peak traction, $\hat{\sigma}_{t}$, is equal to $6 \mathrm{MPa}$ and the interface fracture energy, $\Gamma_{t}$, is $1 \mathrm{~N} / \mathrm{mm}$

law interface parameters are estimations, which agree well with reported literature data, and can be used for purposes of the current study. A more direct test method should be used for accurate measurement of these parameters.

\subsection{Aligned discontinuous tape composites}

Figure 19 shows the finite element predictions for the Young's modulus of the aligned discontinuous SRPP composites with pre-cut tape lengths of 8.8, 13, 18, 20, 30 and $40 \mathrm{~mm}$. Three values for tape Young's modulus after hot-compaction, $E_{t, 11}$, were used and it can be seen that for $E_{t, 11}$ equal to 10 or $10.5 \mathrm{GPa}$, there is a good agreement with the experimental values. For $E_{t, 11}$ is $9 \mathrm{GPa}$, being the value used for the modelling of vacuum bag moulded single tape composites, the predicted Young's modulus is clearly lower than the measured values. Molecular relaxation and property loss is expected to be higher in the single tape model composites than in the aligned discontinuous SRPP composites where the tapes are partially constrained by the lateral pressure arising from the hot-compaction process in a hot-press and thus $E_{t, 11}$ should be somewhat higher than $9 \mathrm{GPa}$. However, still a significant amount of property loss has occurred as the tapes Young's modulus was reduced from 14-15 GPa to $10.5 \mathrm{GPa}$ as a result of relaxation phenomena due to insufficient constraining in the case of cut short tapes as compared to continuous tapes [7, 8]. Interestingly, higher tape moduli values leads to Young's moduli predictions of the composites, which are closer to the experimental values for larger tape lengths. Predictions for shorter tape lengths, on the other hand, are worse and better described by lower tape moduli. Possibly, residual $E_{t, 11}$ after hot-compaction is different for the shorter tape composites and seems to some extend depended on tape length. Tapes of shorter length are more difficult to constrain and 


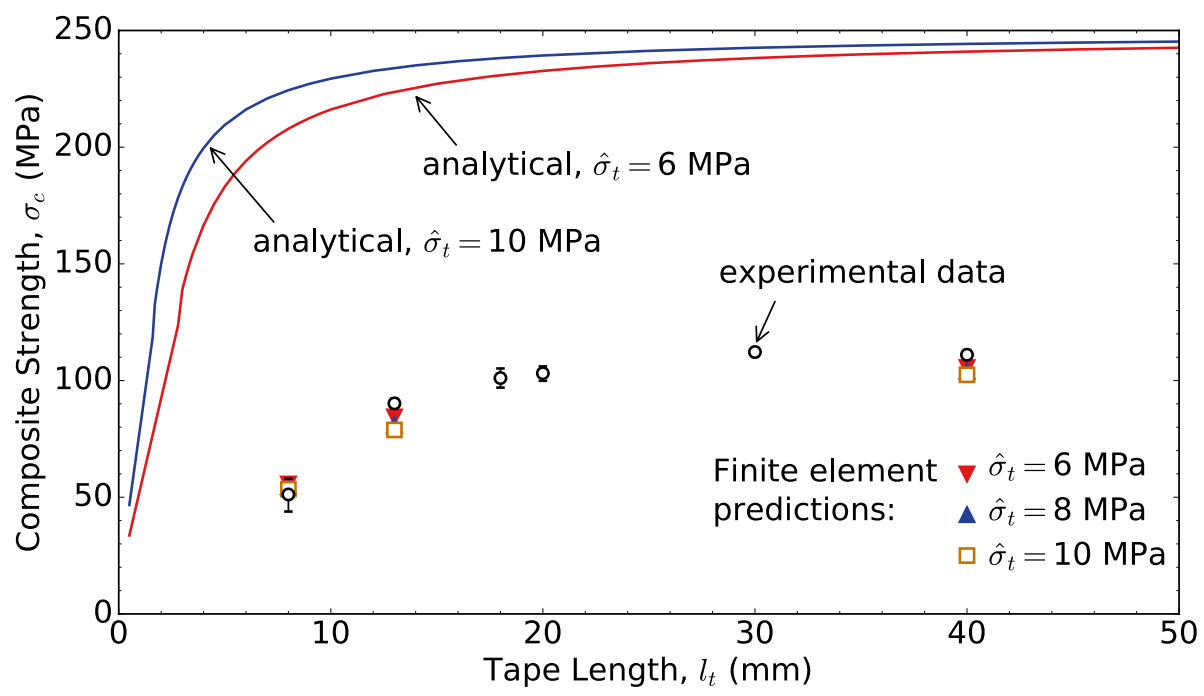

Fig. 20 Comparison of the finite element predictions for the strength of the aligned discontinuous SRPP composites as a function of tape length for three peak tractions, $\hat{\sigma}_{t}$, equal to 6,8 and $10 \mathrm{MPa}$ with the experimental measurements. The analytical predictions using the Eq. 4, with $\sigma_{t, 11}^{u}=400 \mathrm{MPa}$, are also included. The interface fracture energy, $\Gamma_{t}$, is $1 \mathrm{~N} / \mathrm{mm}$ and the Young's modulus of the tapes, $E_{t, 11}=10.5 \mathrm{GPa}$

therefore a lower residual tape modulus can be expected after moulding. For the purposes of the present work e.g. predicting the properties of SRPP composites based on randomly oriented short tapes, Young's modulus values around $10 \mathrm{GPa}$ are of sufficient accuracy.

The analytical predictions based on the modified rule of mixtures are slightly higher than the corresponding finite element predictions. This should be expected as misalignment of the tapes due to waviness and crimp is not taken into account. The discrepancy between the analytical model and the experimental data is larger for shorter tape lengths. For larger tape lengths, the modified rule of mixtures can be used to predict relatively accurately the Young's modulus. Selezneva et al. [52] reached the same conclusion for randomly oriented strand (ROS) composites.

Next, in Fig. 20 the finite element predictions for the strength of discontinuous aligned composites are given as a function of the pre-cut tape length for three different cohesive peak tractions. The Young's modulus of the oriented PP tapes, $E_{t, 11}$, was set to $10.5 \mathrm{GPa}$ based on the results of Fig. 19. It should be noted, however, that variations in $E_{t, 11}$ have a nearly negligible effect on the composite strength. It can be seen that finite element predictions agree well with the experimental data for the three tape lengths modelled. The cohesive (interface) peak traction has a small effect on the composite strength. An increase of the peak traction results in a small decrease of the composite strength.

Based on the finite element predictions, there is significant debonding between the tapes for short pre-cut tape lengths. The debonding initiates where the tapes are cut and extends to the region where the tapes are straight and parallel to the $x$-axis. Simultaneously, the tapes fail themselves again close to the cut locations. Both the tensile tape failure and shear damage criteria are met and extend to the entire region where the tapes are misaligned. However, the final failure mode is predominantly tensile failure of the tape in the misaligned region. Similar failure mode was observed for the large pre-cut tape lengths with 
the difference being that the extend of debonding is significantly smaller and the tape failure is mainly tensile dominated.

Similar to Selezneva et al. [52], the discrepancies between the analytical model and the experimental values are significant and for this reason the modified rule of mixture will not be used in the subsequent Section for the prediction of composites strength based on short randomly oriented tapes.

\subsection{Randomly oriented short tape composites}

Because of experimental difficulties to make truly planar (2D) isotropic short tape SRPP composites of different tape lengths, the mechanical properties of such composites were predicted using finite element analysis. The material properties used were taken from the previous Sections: (i) interface properties from the single tape model composites and (ii) tape properties from the aligned discontinuous tape composites.

Figure 21 shows the Young's modulus of SRPP composites based on randomly oriented short tapes as a function of the tape length for two different tape Young's moduli, $E_{t, 11}$, of 9 and $10.5 \mathrm{GPa}$. For $E_{t, 11}=9 \mathrm{GPa}$, two configurations were considered. In one case, the tape width, $w_{t}$, equals the tape length, $l_{t}$, e.g. both $l_{t}$ and $w_{t}$ increase with tape aspect ratio. In the second configuration, $w_{t}$ is constant and therefore only $l_{t}$ increases with the tape aspect ratio. For comparison purposes, predictions from the modified rule of mixtures, Eq. 4, are also plotted in Fig. 21. It should be noted that even up to a tape aspect ratio equal to 200, the actual tape length is relatively small $(15 \mathrm{~mm})$ and a discrepancy between the analytical model and the finite element predictions should be expected. As can be seen, the composite

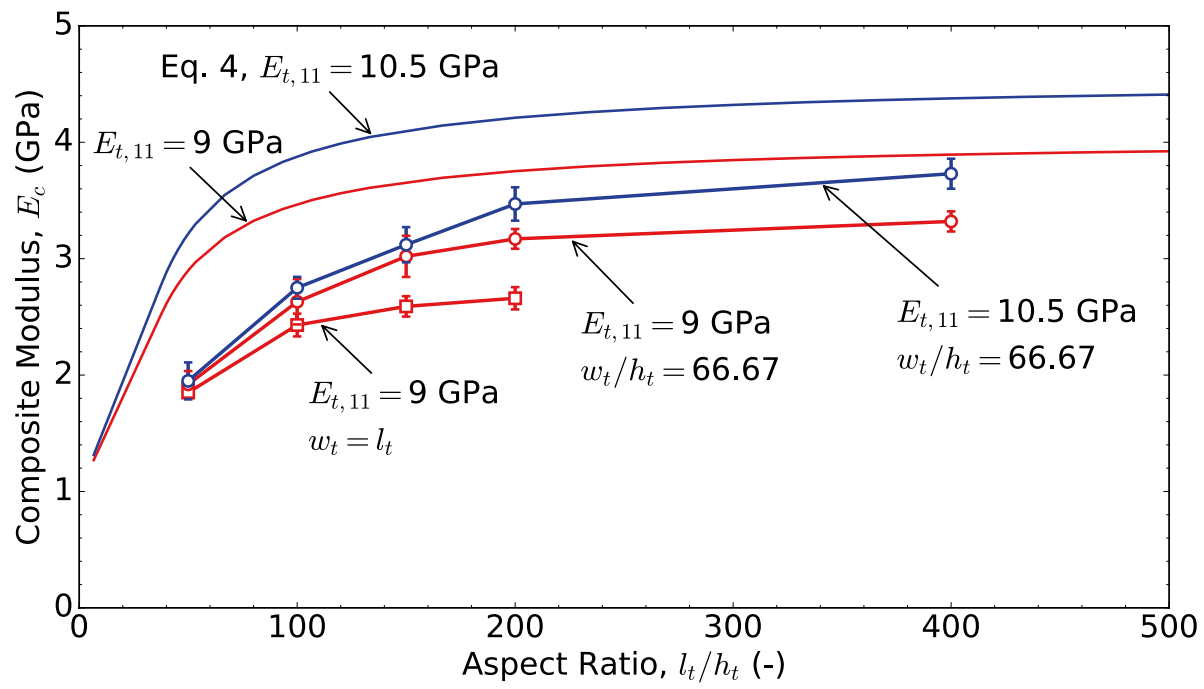

Fig. 21 Finite element predictions for the Young's modulus, $E_{c}$, of randomly oriented discontinuous short tape SRPP composites as a function of tape aspect ratio, $l_{t} / h_{t}$, when the width of the discontinuous tapes equals the length of these tapes and when the width of the discontinuous tapes is constant for two tape Young's moduli $E_{t, 11}$. The cohesive peak traction is equal to $6 \mathrm{MPa}$ and the fracture energy is equal to 1.0 $\mathrm{N} / \mathrm{mm}$. The thickness of the specimen is equal to $12 h_{t}$. The analytical predictions using the modified rule of mixtures, Eq. 4 are also included 


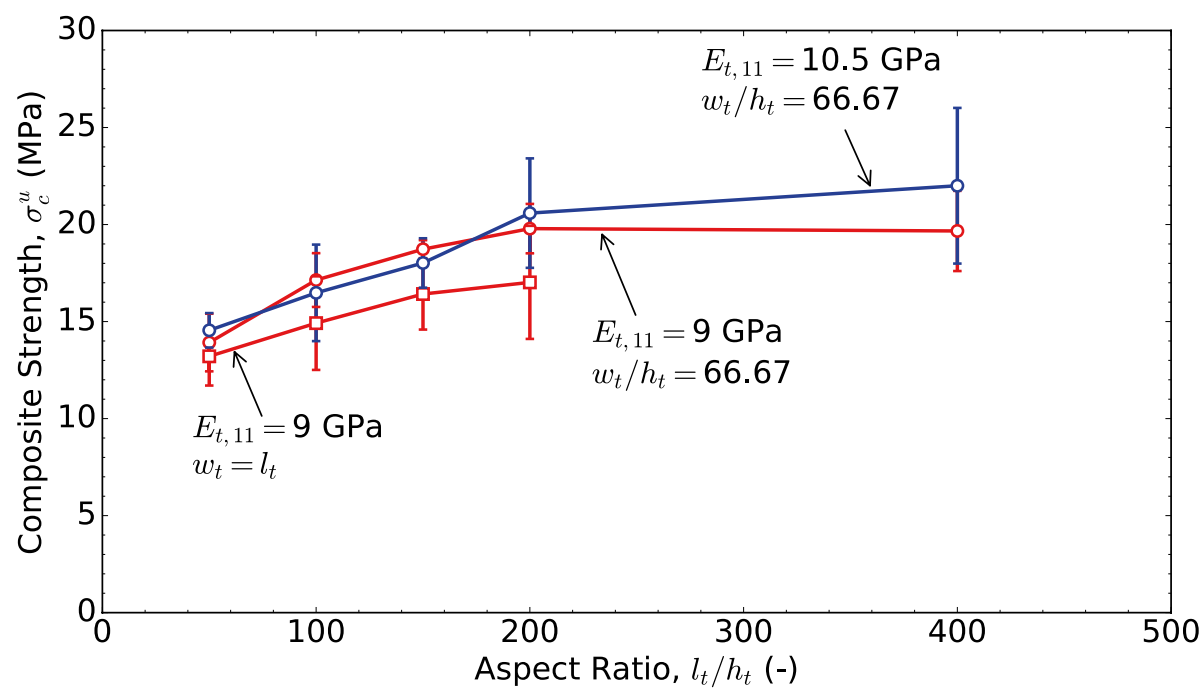

Fig. 22 Finite element predictions for the strength, $\sigma_{c}$, of randomly oriented discontinuous short tape SRPP composites as a function of tape aspect ratio, $l_{t} / h_{t}$, when the width of the discontinuous tapes equals the length of the tapes and when the width of the discontinuous tapes is constant for two Young's moduli $E_{t, 11}$ of the tape. The cohesive peak traction is equal to $6 \mathrm{MPa}$ and the fracture energy equal to $1.0 \mathrm{~N} / \mathrm{mm}$. The thickness of the specimen is equal to $12 h_{t}$

Young's modulus, $E_{c}$, approaches a value of $4 \mathrm{GPa}$, for tape aspect ratios above 100 . This means that for a wide range of tape lengths $(>5 \mathrm{~mm}), E_{c}$ is two to nearly three times higher than that of bulk isotactic PP, with a typical Young's modulus of 1.4-1.5 GPa, as would be obtained by recycling SRPP back into an extruder into a PP blend [60].

The predicted strength of random discontinuous tape SRPP composites as a function of tape aspect ratio and two different tape Young's moduli is shown in Fig. 22. Similar to Fig. 21, every point in Fig. 22 is an average value of 4 simulations. The tape Young's modulus does not have any influence on composite strength, $\sigma_{c}^{u}$. For the two configurations and for the range of aspect ratios examined, the strength of these composites is rather low and similar or even lower than the yield stress of isotropic bulk PP ( 20 MPa). This is due to the rather low shear and transverse strength values of the oriented and highly anisotropic PP tapes and the low shear strength of the copolymer interlayer. The finite element results showed that debonding between the tapes is rather limited. Fracture is by tape tensile failure whereas the shear contribution is small. Thus, the strength of random discontinuous tape SRPP composites is limited by the low strength of the misaligned tapes. Based on Fig. 22, a further increase of the short tape length, $l_{t}$, would only result in a minor composite strength increase.

The results of Fig. 22 refer to a composite thickness equal to the thickness of the discontinuous aligned tape composites, which is rather low $(\leq 1 \mathrm{~mm})$. For such low thicknesses, there is a high probability of having a weak cross-section along the specimen thickness (see Fig. 9). Several additional simulations were performed for an increased composite thicknesses to examine the size effect on composite strength. For an aspect ratio equal to 200 and material properties similar to Fig. 22 it was found that a three times increase of the thickness, only resulted in a composite strength of 25-30 MPa (see Online Resource Fig. $\mathrm{S} 2$ ). Thus, although higher, this value is still only marginally higher than the yield stress 
isotropic bulk PP. Thus, although there is a size effect on composite laminate strength, the potential for significantly increasing the tensile strength is rather limited.

\section{Conclusions}

The mechanical properties and subsequently the potential of recycling SRPP tapes or fabrics into short tape SRPP composites was examined. Mechanical tests and finite element simulations at different length scales were performed to extract the materials properties necessary for the numerical modelling of 2D random discontinuous tape SRPP composites.

- The Digital Image Correlation strain mapping technique was used to measure the local matrix strains near the tape/matrix interface in single tape model composites. The experimental results were used in finite element simulations to indirectly extract interface properties described by a cohesive law.

- Aligned discontinuous tape model composites were made from pre-cut layers of plain weave fabrics of coextruded PP tapes. The length of the pre-cut tapes was varied and the composites were tested in tension. The experimental results, stiffness and strength, were used to validate the finite element model used later to model the randomly oriented short tape SRPP composites, while interface properties were taken from the single tape model composites.

- The material properties extracted from the single tape and aligned discontinuous tape model composites (experimental validation and finite element analysis) were used to predict the stiffness of SRPP composites based on in-plane randomly oriented short tapes. It was found that the stiffness of these composites is expected to be nearly three times that of bulk PP, as obtained by remelting and recompounding. However, the strength of these composites was similar to that of bulk PP.

- In light of the present results and the difficulty to use flow moulding processes because of the near absence of matrix material in these coextruded tapes, the potential of recycling coextruded SRPP tapes or fabrics into short tape SRPP composites seems therefore limited. In fact, from a cost-benefit point of view, mechanical recycling schemes based on simple recompounding processes might often be more beneficial.

Open Access This article is licensed under a Creative Commons Attribution 4.0 International License, which permits use, sharing, adaptation, distribution and reproduction in any medium or format, as long as you give appropriate credit to the original author(s) and the source, provide a link to the Creative Commons licence, and indicate if changes were made. The images or other third party material in this article are included in the article's Creative Commons licence, unless indicated otherwise in a credit line to the material. If material is not included in the article's Creative Commons licence and your intended use is not permitted by statutory regulation or exceeds the permitted use, you will need to obtain permission directly from the copyright holder. To view a copy of this licence, visit http://creativecommons.org/licenses/by/4.0/.

\section{References}

1. Mallick, PK.: Particulate and short fiber reinforced polymer composites. In: Kelly A, Zweben C (eds) Comprehensive Composite Materials. Elsevier Science \& Technology. Oxford. 2, 291-331 (2000)

2. Fu, SY. Lauke, B. Mai, YW.: Science and engineering of short fibre reinforced polymer composites. Woodhead Publishing. (2009) 
3. Ward, IM. Hine, PJ.: The science and technology of hot compaction. Polymer. 45(5), 1413-1427 (2004)

4. Peijs, T.: Composites for recyclability. Materials Today. 4(6), 30-5 (2003)

5. Alcock, B., Peijs, T.: Technology and development of self-reinforced polymer composites. In: Polymer composites - polyolefin fractionation - polymeric peptidomimetics - collagens. Advances in Polymer Science. Heidelberg. Springer. Berlin. 1-76 (2011)

6. Hine, PJ., Ward, IM., Jordan, ND., Olley, R., Bassett, DC.: The hot compaction behaviour of woven oriented polypropylene fibres and tapes. i. mechanical properties. Polymer. 44(4),1117-1131 (2003)

7. Alcock, B., Cabrera, NO., Barkoula, NM., Loos, J., Peijs, T.: The mechanical properties of unidirectional all-polypropylene composites. Composites Part A: Applied Science and Manufacturing. 37(5), 716-726 (2006)

8. Alcock, B., Cabrera, NO., Barkoula, NM., Spoelstra, AB.,Loos, J., Peijs, T.: The mechanical properties of woven tape all-polypropylene composites. Composites Part A: Applied Science and Manufacturing. 38(1), 147-161 (2007)

9. Rasburn, J., Hine, PJ., Ward, IM., Olley, RH.,Bassett, DC., Kabeel, MA.: The hot compaction of polyethylene terephthalate. Journal of Materials Science. 30(3), 615-22 (1995)

10. Zhang, JM., Reynolds, CT., Peijs, T.: All-poly(ethylene terephthalate) composites by film stacking of oriented tapes. Composites Part A: Applied Science and Manufacturing. 40(11), 1747-1755 (2009)

11. Zhang, JM., Peijs, T.: Self-reinforced poly(ethylene terephthalate) composites by hot consolidation of bi-component pet yarns. Composites Part A: Applied Science and Manufacturing. 41(8), 964$972(2010)$

12. Hine, PJ., Ward, IM., Olley, RH., Bassett, DC.: The hot compaction of high modulus melt-spun polyethylene fibres. Journal of Materials Science. 28(2), 316-324 (1993)

13. Yan, RJ., Hine, PJ., Ward, IM. ,Olley, RH., Bassett, DC.: The hot compaction of spectra gel-spun polyethylene fibre. Journal of Materials Science. 32(18), 4821-4832 (1997)

14. Mai, F., Tu, W., Bilotti, E., Peijs, T.: Preparation and properties of self-reinforced poly(lactic acid) composites based on oriented tapes. Composites Part A: Applied Science and Manufacturing. 76, $145-153$ (2015)

15. Goutianos, S., Van der Schueren, L., Beauson, J0.: Failure mechanisms in unidirectional self-reinforced biobased composites based on high stiffness PLA fibres. Composites Part A: Applied Science and Manufacturing. 117, 169-179 (2019)

16. Schaller, R., Peijs, T., Tervoort, TA.: High-performance liquid-crystalline polymer films for monolithic "composites". Composites Part A: Applied Science and Manufacturing. 81, 296-304 (2016)

17. Zhang, JM., Mousavi, Z., Soykeabkaew, N., Smith, P., Nishino, T., Peijs, T.: All-aramid composites by partial fiber dissolution. ACS Applied Materials \& Interfaces. 2(3), 919-926 (2010)

18. Nishino, T., Matsuda, I., Hirao, K.: All-cellulose composite. Macromolecules. 37(20), 7683-7687 (2004)

19. Soykeabkaew, N., Sian, C., Gea, S., Nishino, T., Peijs, T.: All-cellulose nanocomposites by surface selective dissolution of bacterial cellulose. Cellulose. 16(3), 435-444 (2009)

20. Loos, J., Jacobs, JA.,Peijs, AA., Schimanski, T.: Polyolefin film, tape or yarn. United States. patent US. assignee: Lankhorst Indutech BV. 7(318), 961 (1997)

21. Cabrera, N., Alcock, B., Loos, J., Peijs, T.: Processing of all-polypropylene composites for ultimate recyclability. Proceedings of the Institution of Mechanical Engineers, Part L: Journal of Materials: Design and Applications. 218(2), 145-155 (2004)

22. Alcock, B., Cabrera, NO., Barkoula, NM., Loos, J., Peijs, T.: Interfacial properties of highly oriented coextruded polypropylene tapes for the creation of recyclable all polypropylene composites. Journal of Applied Polymer Science. 104(1), 118-129 (2007)

23. Cabrera, NO., Alcock, B., Klompen, ET., Peijs, T.: Filament winding of co-extruded polypropylene tapes for fully recyclable all-polypropylene composite products. Applied Composite Materials. 15(1), 27-45 (2008)

24. Cabrera, NO., Reynolds, CT., Alcock, B., Peijs, T.: Non-isothermal stamp forming of continuous tape reinforced all-polypropylene composite sheet. Composites Part A: Applied Science and Manufacturing. 39(9), 1455-1466 (2008)

25. Alcock, B., Cabrera, NO., Barkoula, NM., Peijs, T.: Direct forming of all-polypropylene composites products from fabrics made of co-extruded tapes. Applied Composite Materials. 16(2), 117-34 (2009)

26. Peijs, T.: Natural fiber based composites. Materials Technology. 15(4), 281-285 (2000)

27. Alcock, B., Cabrera, NO., Barkoula, NM., Peijs, T.: The effect of processing conditions on the mechanical properties and thermal stability of highly oriented PP tapes. European Polymer Journal. 45(10), 2878-2894 (2009) 
28. Loos, J., Schimanski, T., Hofman, J., Peijs, T., Lemstra, PJ.: Morphological investigations of polypropylene single-fibre reinforced polypropylene model composites. Polymer. 42(8), 3827-3834 (2001)

29. Barkoula, NM., Peijs, T., Schimanski, T., Loos, J.: Processing of single polymer composites using the concept of constrained fibers. Polymer composites. 26(1), 114-120 (2005)

30. Belytschko, T., Liu, WK., Brian, M.: Nonlinear Finite Elements for Continua and Structures. John Wiley \& Sons. Ltd (2000)

31. Goutianos, S., Sørensen, BF.: Fracture resistance enhancement of layered structures by multiple cracks. Engineering Fracture Mechanics. 151, 92-108 (2016)

32. Cox, H.L.: The elasticity and strength of paper and other fibrous materials. British Journal of Applied Physics. 3(3), 72-79 (1952)

33. Kelly, A., Tyson, AW.: Tensile properties of fibre-reinforced metals: copper/tungsten and copper/ molybdenum. Journal of the Mechanics and Physics of Solids. 13(6), 329-350 (1965)

34. Piggott, MR.: Expressions governing stress-strain curves in short fibre reinforced polymers. Journal of Materials Science. 13(8), 1709-1716 (1978)

35. Tripathi, D., Jones, FR.: Single fibre fragmentation test for assessing adhesion in fibre reinforced composites. Journal of Materials Science. 33(1), 1-6 (1998)

36. Van den Heuvel, PW., Hogeweg, B., Peijs, T.: An experimental and numerical investigation into the single-fibre fragmentation test: stress transfer by a locally yielding matrix. Composites Part A: Applied Science and Manufacturing. 28(3), 237-249 (1997)

37. Hsueh, C.H.: A two-dimensional stress transfer model for platelet reinforcement. Composites Engineering. 4(10), 1033-1043 (1994)

38. Hsueh, C.H.: Some applications of two-dimensional stress transfer analyses. Acta Materialia. 46(6), 2131-2138 (1998)

39. Sørensen, B.F.: Micromechanical model of the single fiber fragmentation test. Mechanics of Materials. 104, 38-48 (2017)

40. Dugdale, D.S.: Yielding of steel sheets containing slits. Journal of the Mechanics and Physics of Solids. 8, 100-104 (1960)

41. Barenblatt, G.: The mathematical theory of equilibrium cracks in brittle fracture. Advances in Applied Mechanics. 7, 55-129 (1962)

42. ABAQUS.: Version 6.17. Dassault Systèmes Simulia Corp. Providence. RI. United States. (2017)

43. Turon, A., Dávila, CG., Camanho, P., Costa, J.: An engineering solution for mesh size effects in the simulation of delamination using cohesive zone models. Engineering fracture mechanics. 10, 1665-1682 (2007)

44. Goutianos, S., Sørensen, BF.: The application of J integral to measure cohesive laws under largescale yielding. Engineering Fracture Mechanics. 155, 145-165 (2016)

45. Path dependence of truss-like mixed mode cohesive laws: Goutianos, S. Sørensen, BF. Engineering Fracture Mechanics. 91, 117-132 (2012)

46. Deng, H., Reynolds, CT., Cabrera, N., Barkoula, NM., Alcock, B., Peijs, T.: The water absorption behaviour of all-polypropylene composites and its effect on mechanical properties. Composites Part B: Engineering. 41(4), 268-275 (2010)

47. Hashin, Z.: Failure criteria for unidirectional fiber composites. Journal of Applied Mechanics. 47, 329-334 (1980)

48. Hashin, Z., Rotem, A.: A fatigue criterion for fiber-reinforced materials. Journal of Composite Materials. 7, 448-464 (1973)

49. Jin, BC., Li, X., Jain, A., González, C., LLorca, J., Nutt, S.: Optimization of microstructures and mechanical properties of composite oriented strand board from reused prepreg. Composite Structures. 174, 389-398 (2017)

50. Kravchenko, SG., Sommer, DE., Denos, BR., Favaloro, AJ., Tow, CM., Avery, WB., Pipes, RB.: Tensile properties of a stochastic prepreg platelet molded composite. Composites Part A: Applied Science and Manufacturing. 124, 105507 (2019)

51. Sommer, DE., Kravchenko, SG., Denos, BR., Favaloro, AJ., Pipes, RB.: Integrative analysis for prediction of process-induced, orientation-dependent tensile properties in a stochastic prepreg platelet molded composite. Composites Part A: Applied Science and Manufacturing. 130, 105759 (2020)

52. Selezneva, M., Roy, S., Lessard, L., Yousefpour, A.: Analytical model for prediction of strength and fracture paths characteristic to randomly oriented strand (ros) composites. Composites Part B: Engineering. 96, 103-111 (2016)

53. Tucker III, C., Liang, E.: Stiffness predictions for unidirectional short-fiber composites: Review and evaluation. Composites Science and Technology. 59(5), 655-671 (1999) 
54. Alcock, B.: Single polymer composites based on polypropylene: Processing and properties. PhD thesis, School of engineering and Materials Science. Queen Mary University of London. (2004)

55. Thomason, JL., Schoolenberg, GE.: An investigation of glass fibre/polypropylene interface strength and its effect on composite properties. Composites. 25(3), 197-203 (1994)

56. Thomason, J.L.: Interfacial strength in thermoplastic composites - At last an industry friendly measurement method? Composites Part A: Applied Science and Manufacturing 33(10), 1283-1288 (2002)

57. Jannerfeldt, G., Törnqvist, R., Rambert, N., Boogh, L., Månson, JA.: Matrix modification for improved reinforcement effectiveness in polypropylene/glass fibre composites. Applied Composite Materials. $8(5), 327-341$ (2001)

58. Fracture studies on polypropylene: Sims, GLA. Journal of Materials Science 10, 647-657 (1975)

59. Mahajan, SJ., Deopura, BL., Wang, Y.: Structure-morphology and tear strength of oriented tapes of polyethylene and its blends III. Journal of Applied Polymer Science. 60, 1539-1549 (1996)

60. Weager, BM., Bishop, GR., Black, AC., Reynolds, N., Pharaoh, MW., Smith, GF., Rowe, J., Riley, DE., Birrell, M., Donaldson, P.: Development of recyclable self-reinforced polypropylene parts for automotive applications. International Journal of Vehicle Design. 44(3-4), 293-310 (2007)

Publisher's Note Springer Nature remains neutral with regard to jurisdictional claims in published maps and institutional affiliations. 